\title{
Development of carbohydrate-based nano-microstructures loaded with fish oil by using electrohydrodynamic processing
}

\author{
García Moreno, Pedro Jesús; Özdemir, N.; Boutrup Stephansen, Karen; Mateiu, Ramona Valentina; \\ Echegoyend, Y. ; Lagaron, J.M. ; Chronakis, loannis S.; Jacobsen, Charlotte
}

\section{Published in:}

Food Hydrocolloids

Link to article, DOI:

10.1016/j.foodhyd.2017.02.013

Publication date:

2017

Document Version

Peer reviewed version

Link back to DTU Orbit

\section{Citation $(A P A)$ :}

García Moreno, P. J., Özdemir, N., Boutrup Stephansen, K., Mateiu, R. V., Echegoyend, Y., Lagaron, J. M., Chronakis, I. S., \& Jacobsen, C. (2017). Development of carbohydrate-based nano-microstructures loaded with fish oil by using electrohydrodynamic processing. Food Hydrocolloids, 69, 273-285.

https://doi.org/10.1016/j.foodhyd.2017.02.013

\section{General rights}

Copyright and moral rights for the publications made accessible in the public portal are retained by the authors and/or other copyright owners and it is a condition of accessing publications that users recognise and abide by the legal requirements associated with these rights.

- Users may download and print one copy of any publication from the public portal for the purpose of private study or research.

- You may not further distribute the material or use it for any profit-making activity or commercial gain

- You may freely distribute the URL identifying the publication in the public portal 


\section{Accepted Manuscript}

Development of carbohydrate-based nano-microstructures loaded with fish oil by using electrohydrodynamic processing

Pedro J. García-Moreno, Necla Özdemir, Karen Stephansen, Ramona V. Mateiu, Yolanda Echegoyen, Jose M. Lagaron, Ioannis S. Chronakis, Charlotte Jacobsen

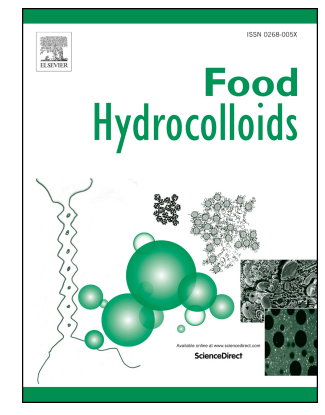

PII:

S0268-005X(16)30671-3

DOI:

10.1016/j.foodhyd.2017.02.013

Reference: FOOHYD 3802

To appear in: Food Hydrocolloids

Received Date: 26 October 2016

Revised Date: 27 January 2017

Accepted Date: 19 February 2017

Please cite this article as: García-Moreno, P.J., Özdemir, N., Stephansen, K., Mateiu, R.V., Echegoyen, Y., Lagaron, J.M., Chronakis, I.S., Jacobsen, C., Development of carbohydrate-based nanomicrostructures loaded with fish oil by using electrohydrodynamic processing, Food Hydrocolloids (2017), doi: 10.1016/j.foodhyd.2017.02.013.

This is a PDF file of an unedited manuscript that has been accepted for publication. As a service to our customers we are providing this early version of the manuscript. The manuscript will undergo copyediting, typesetting, and review of the resulting proof before it is published in its final form. Please note that during the production process errors may be discovered which could affect the content, and all legal disclaimers that apply to the journal pertain. 


\section{Fish oil rich in omega-3 PUFA}
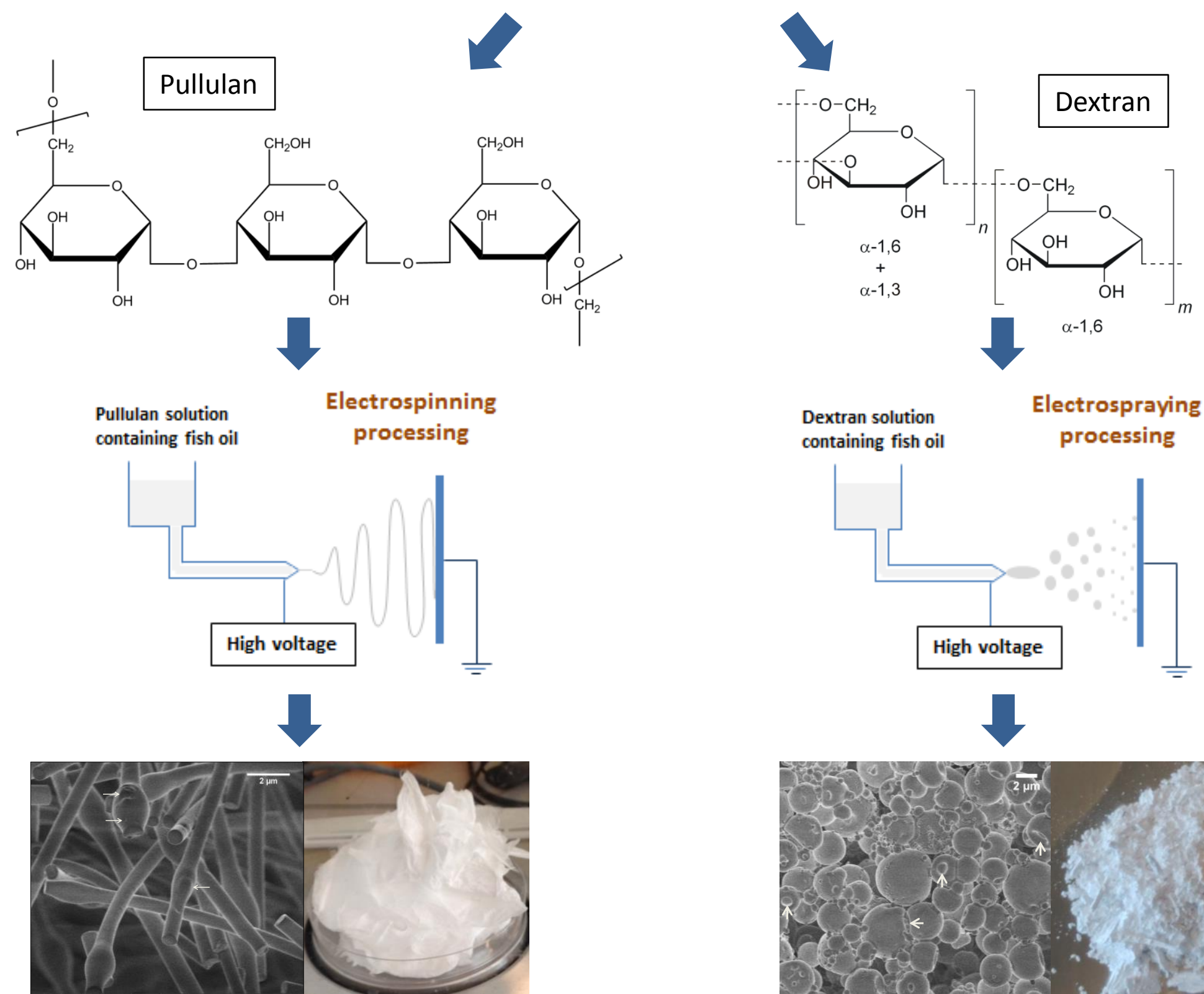

Fish oil-loaded pullulan nanofibers

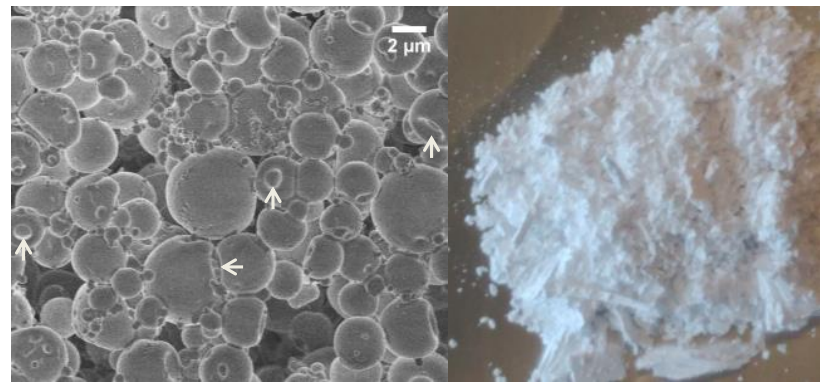

Fish oil-loaded dextran nanocapsules 
1 DEVELOPMENT OF CARBOHYDRATE-BASED

NANO-

2 MICROSTRUCTURES LOADED WITH FISH OIL BY USING

3 ELECTROHYDRODYNAMIC PROCESSING

4 Pedro J. García-Moreno* ${ }^{\text {a* }}$, Necla Özdemir ${ }^{\text {a,b }}$, Karen Stephansen ${ }^{\text {a }}$, Ramona V. Mateiu ${ }^{c}$, Yolanda

5 Echegoyen $^{\mathrm{d}, \dagger}$, Jose M. Lagaron ${ }^{\mathrm{d}}$, Ioannis S. Chronakis ${ }^{\mathrm{a}}$, Charlotte Jacobsen ${ }^{\mathrm{a}}$

$6 \quad{ }^{a}$ Division of Food Technology, National Food Institute, Technical University of Denmark, Denmark

$7 \quad{ }^{\mathrm{b}}$ Food Engineering Department, Ankara University, Turkey

$8 \quad{ }^{\mathrm{c}}$ DTU CEN, Center for Electron Nanoscopy, Technical University of Denmark, Denmark

$9{ }^{\mathrm{d}}$ Novel Materials and Nanotechnology Group, IATA-CSIC, Spain

$10 \dagger$ Present address: Science Education Department, Facultat de Magisteri, Universitat de València, 11 Spain

ABSTRACT

The encapsulation of fish oil in carbohydrate-based nanomicrostructures obtained by electrohydrodynamic processing was investigated. Solutions of pullulan $200 \mathrm{kDa}(15 \mathrm{wt} \%)$ and dextran $70 \mathrm{kDa}(25 \mathrm{wt} . \%)$ presented appropriate properties (viscosity, surface tension and conductivity) to allow the formation of nano-microfibers and nano-microcapsules, respectively. Although dextran $70 \mathrm{kDa}$ exhibited antioxidant properties in solution, their capsules produced at lab and pilot-plant scales showed a low oxidative stability both with emulsified and neat oil. Phase separation of solution and opened capsules indicated a poor interaction between dextran and fish oil, which suggested that further optimization of the electrospraying solution is necessary. On the contrary, pullulan solutions were optimized to work even at pilot-plant scale. In this case, in spite of the prooxidant effect of pullulan in solution, oxidatively stable pullulan fibers $\left(\mathrm{PV}=12.3 \pm 0.9 \mathrm{meq} \mathrm{O}_{2} / \mathrm{kg}\right.$ and $15.5 \pm 5.1 \mathrm{ng} / \mathrm{g}$ of 1-penten-3-ol) were obtained when oil was incorporated as neat oil and when producing batches during short time (30 or $10 \mathrm{~min}$ ). This superior oxidative stability when compared to fibers with emulsified oil is mainly attributed to a higher fish oil entrapment and to the location of the oil in large bead-structures with a reduced specific surface area. These results indicated the

\footnotetext{
* Corresponding author. Tel: +45 2525 59; Fax: +45 458847 74; E-mail: pejeg@food.dtu.dk
} 
feasibility of producing omega-3 nanodelivery systems by encapsulating fish oil in pullulan nanomicrofibers using electrospinning processing.

Keywords: fish oil, pullulan, dextran, electrohydrodynamic processing, oxidative stability

\section{INTRODUCTION}

Long chain omega-3 polyunsaturated fatty acids (omega-3 PUFA), specially eicosapentaenoic (C20:5n-3, EPA) and docosahexaenoic (C22:6n-3, DHA) acids, provide numerous beneficial effects on human health such as prevention of cardiovascular diseases, improvement of anti-inflammatory and allergic responses and development of brain and eye retina (Shahidi, 2015). As a consequence, the demand of functional food and infant formulations enriched with these lipids, continues to increase in North America and Europe, and it is expected to grow considerably in Asia through the next decade (GOED, 2015). However, omega-3 PUFA are highly susceptible to oxidation and has a low solubility in most food systems, which limit their use as nutritionally beneficial lipids in food (Encina, Vergara, Giménez, Oyarzún-Ampuero, \& Robert, 2016). To overcome these drawbacks, encapsulation of omega-3 PUFA is commonly carried out, which makes it possible to mask their unpleasant taste and odor and to protect these highly unsaturated fatty acids against prooxidants (e.g. oxygen, light, free radicals and metal ions) (Comunian \& Favaro-Trindade, 2016).

Electrohydrodynamic processing is an emerging encapsulation technique, which has been used to obtain submicron encapsulates for both hydrophilic (bifidobacterium strain - López-Rubio, Sanchez, Wilkanowicz, Sanz, \& Lagaron, 2012; ferulic acid - Yang, Zha, Yu, \& Liu, 2013; gallic acid- Neo, Ray, \& Jin, 2013 and (-)-epigallocatechin gallate - Gómez-Mascaraque, Sanchez, \& López-Rubio, 2016) and hydrophobic ( $\beta$-carotene - López-Rubio \& Lagaron, 2012; curcumin - Brahatheeswaran et al., 2012; and lycopene - Pérez-Masiá, Lagaron, \& Lopez-Rubio, 2015) bioactive compounds. The process employs a high-voltage electro-static field to charge the surface of a polymer solution droplet at the end of a capillary tube. As a consequence of mutural charge respulsion, the droplet elongates forming a conical shape known as the Taylor cone. When the electric field applied overcomes the surface tension of the droplet, a charged jet of polymer solution is ejected from the tip of the Taylor 
53

54

55

56

57

58

cone. If the jet is stable (e.g. due to high polymer chain entanglements), the process is called electrospinning and micro- or nanofibers are produced after evaporation of the solvent during elongation of the jet as a consequence of several instabilities (e.g. whipping or bending motions). On the other hand, in the electrospraying process, due the low viscoelasticity of the polymer solution, the jet subsequently breaks up and deposits on a grounded or oppositely charged collector as fine particles (Ghorani \& Tucker, 2015). Alternatively to the most common microencapsulation technique (spraydrying), electrohydrodynamic processes (e.g. electrospinning or electrospraying) do not require the use of a heated air stream, which avoids the deterioration of thermo- and oxygen-sensitive bioactive compounds (Lim, 2015). Moreover, and contrarily to freeze-drying, electrohydrodynamic processes can be up-scaled and run in continuous operation mode. In addition, nano-microstructures (NMS) (e.g. fibers or capsules) obtained by electrohydrodynamic processing present a reduced size $(0.1-5 \mu \mathrm{m})$, which makes them easier to disperse in food matrices when compared to encapsulates produced by traditional (e.g. spray- and freeze-drying, 1-100 $\mu \mathrm{m}$ ) or other emerging encapsulation techniques (e.g. co-acervation, 5-200 $\mu \mathrm{m}$; and extrusion, 15-2000 $\mu \mathrm{m}$ ) (Barrow, Wang, Adhikari, \& Liu, 2013).

Food-grade NMS are obtained by using biopolymers (e.g. proteins, polysaccharides), bio-compatible polymers (e.g. poly-vinyl alcohol, PVA; polyethylene oxide, PEO) or their blends which are dissolved in solvents approved for food applications (e.g. water, alcohols, formic and acetic acids) (Weiss, Kanjanapongkul, Wongsasulak, \& Yoovidhya, 2012). Common proteins used as encapsulating materials are zein (Yang et al., 2013; Neo et al., 2013; Brahatheeswaran et al., 2012), whey protein concentrate (WPC) (López-Rubio \& Lagaron, 2012; Pérez-Masiá et al., 2015; Gómez-Mascarque, Morfin, Pérez-Masiá, Sanchez, \& Lopez-Rubio, 2016) and gelatin (Li, Zheng, \& Han, 2006). Other food-grade protein-based nano-microfibers have been obtained by using blends such as soy protein isolate (SPI)-PVA (Cho, Netravali, \& Joo, 2012), egg albumen-cellulose acetate (Wongsasulak, Patapeejumruswong, Weiss, Supaphol, \& Yoovidhya, 2010) and amaranth protein-pullulan (AceitunoMedina, Mendoza, Lagaron, \& Lopez-Rubio, 2015). A great variety of polysaccharides, such as pullulan (López-Rubio et al., 2012), dextran (Pérez-Masiá et al., 2015), chitosan (Gómez-Mascaraque 
et al., 2016a), starch (Pérez-Masiá, Lagaron, \& Lopez-Rubio, 2014), chitosan-alginate blend (Lertsutthiwong \& Rojsitthisak, 2011) and alginate-pectin-PEO blend (Alborzi, Lim, \& Kakuda, 2010), have also been employed as wall materials for the production of bioactive delivery-systems. Nevertheless, to the best of the authors' knowledge, omega-3 PUFA encapsulates have only been obtained by electrohydrodynamic processing when using PVA (García-Moreno et al., 2016) or proteins such as zein (Torres-Giner, Martinez-Abad, Ocio, \& Lagaron, 2010; Moomand \& Lim., 2014) and more recently SPI, gelatin and WPC (Gómez-Mascaraque \& López-Rubio, 2016). In this regard, it is worth noting that, contrarily to proteins, polysaccharides are suitable shell material under high temperature processes due to their thermal stability (Fathi, Martín, \& McClements, 2014). Thus, they may increase the protection of omega-3 PUFA encapsulates when incorporated into food products requiring heating for their production (e.g. baked products).

Therefore, this work aimed to study the development of carbohydrate-based encapsulates containing omega-3 PUFA by electrohydrodynamic processes. Particularly, two neutral polysaccharides of microbial origin, namely pullulan and dextran, were evaluated as encapsulating materials. Pullulan is a linear glucan consisting of maltotriose units connected by $\alpha-1,6$ glycosidic bonds; whereas dextran has a branched structure with $\alpha$-1,6-glucose-linkages with side-chains attached to the 3-positions of the backbone glucose units. Both polysaccharides are water soluble, biocompatible and biodegradable, and are used in food and pharmaceutical applications (Park \& Khan, 2009). First, the influence of polysaccharide concentration on the physical properties (e.g. viscosity, conductivity and surface tension) of the solutions and on the morphology of NMS loaded with fish oil was assayed. Secondly, the oxidative stability during storage of polysaccharide solutions containing fish oil was determined. Finally, selected NMS (e.g. pullulan nano-microfibers and dextran nano-microcapsules) were produced, both in lab and pilot-plant scale, by incorporating the fish oil as emulsified or as neat oil. The effect of the oil-incorporation approach on the morphology, lipid distribution and oxidative stability of the NMS was investigated. 


\section{MATERIALS AND METHODS}

105

106

107

108

109

110

111

112

113

114

115

116

\subsection{Materials}

Pullulan (molecular weight $=200,000$ Da) was kindly donated by Hayashibara Co., Ltd. (Okayama, Japan). Dextran (molecular weight $=70,000 \mathrm{Da}$, dextran70) was generously provided by Pharmacosmos A/S (Holbaek, Denmark). Dextran (molecular weight = 500,000 Da, dextran500) was kindly supplied by Dextran Products Limited (Ontario, Canada). Whey protein concentrate (WPC), under the commercial name of Lacprodan ${ }^{\circledR}$ DI-8090, was kindly donated by ARLA Food Ingredients (Viby, Denmark). Commercial cod liver oil was kindly provided by Maritex A/S, subsidiary of TINE, BA (Sortland, Norway) and stored at $-40{ }^{\circ} \mathrm{C}$ until use. The fatty acid composition of the fish oil was determined by fatty acid methylation (AOCS, 1998a) followed by separation through GC (AOCS, 1998b). It was (major fatty acids only) as follows: C16:0, 9.5\%; C16:1, 8.7\%; C18:1, 16.3\%; C20:1, 12.6\%; C20:5, 9.2\% and C22:6, 11.4\%. The tocopherol content of the fish oil was: $\alpha$-tocopherol, $200 \pm 3 \mu \mathrm{g} / \mathrm{g}$ oil; $\beta$-tocopherol, $5 \pm 1 \mu \mathrm{g} / \mathrm{g}$ oil; $\gamma$-tocopherol, $96 \pm 3 \mu \mathrm{g} / \mathrm{g}$ oil and $\delta$-tocopherol, $47 \pm 1 \mu \mathrm{g} / \mathrm{g}$ oil (AOCS, 1998c). The peroxide value (PV) of the fish oil used was $0.38 \pm 0.04 \mathrm{meq} / \mathrm{kg}$ oil. Whey protein isolate (WPI), with commercial name Laprodan ${ }^{\circledR}$ DI-9224, was kindly donated by ARLA Food Ingredients. All other chemicals and solvents used were of analytical grade.

\subsection{Preparation of biopolymer solutions containing fish oil}

For the evaluation of the influence of biopolymer type and concentration on solution properties and NMS morphology, polysaccharides were assayed at the following concentrations: pullulan, 5-10-15 wt.\%; dextran70, 20-30-40 wt.\%; and dextran500, 10-20-30 wt.\%. NMS morphology was also studied when using a solution of dextran70 at $25 \mathrm{wt} . \%$. The selected ranges of concentration aimed to obtain different nano-microstructures morphology (e.g. fibers or capsules), and they are based on the type and molecular weight of the biopolymers. WPC, which has been widely used for the encapsulation of bioactives, was also tested as a control at 10-20-30 wt.\%. Biopolymers were dissolved in distilled water under constant stirring at room temperature. Fish oil, accounting for $10 \mathrm{wt} \%$ with respect to biopolymer, was added as $10 \mathrm{wt} . \%$ fish oil-in-water emulsion stabilized with $1 \mathrm{wt} . \% \mathrm{WPI}$ at $\mathrm{pH}$ 7. The 
homogenization process was carried out by using a microfluidizer (M110L Microfluidics, Newton,

131 MA, USA) as described elsewhere (García-Moreno, Guadix, Guadix, \& Jacobsen, 2016), resulting in

132 an emulsion with $\mathrm{D}_{3,2}=134 \pm 1 \mathrm{~nm}$. The biopolymer solutions and the fish oil-in-water emulsion were

133 mixed under nitrogen atmosphere by using magnetic stirring for $30 \mathrm{~min}$ at $5{ }^{\circ} \mathrm{C}$ in the dark. Samples

134 were used immediately after production for electrospinning processing and subsequently stored at $5{ }^{\circ} \mathrm{C}$

135 in the dark until analysis of solution properties.

136 Selected solutions, namely $15 \mathrm{wt} . \%$ pullulan and $25 \mathrm{wt} . \%$ of dextran70, were prepared for studying the

137 oxidative stability of NMS. Fish oil was incorporated both as emulsion (as previously described) and

138 as neat oil by using 20 wt.\% Tween-20 (with respect to fish oil) as emulsifier. Tween-20 was added to

139 the biopolymer solution and mixed using mechanical stirring for $10 \mathrm{~min}$ at $500 \mathrm{rpm}$ under nitrogen

140 atmosphere. Subsequently, neat fish oil, accounting for the 10 wt.\% of the biopolymer, was dispersed

141 in the previous solution using mechanical stirring for $20 \mathrm{~min}$ at $500 \mathrm{rpm}$ under nitrogen atmosphere.

142 Samples were used immediately after production for electrospinning and electrospraying.

\subsection{Characterization of solutions}

144 The different biopolymer solutions containing emulsified fish oil were characterized in terms of

145 viscosity, conductivity, surface tension, droplet size distribution and oxidative stability.

\section{$146 \quad$ 2.3.1 Viscosity, surface tension and conductivity}

147 Viscosity was measured using a stress controlled rheometer Stresstech (Reologica Instruments AB,

148 Lund, Sweden) equipped with a CC25 standard bob cup system in a temperature vessel at $25^{\circ} \mathrm{C}$.

149 Surface tension was measured using the Wilhelmy plate method at room temperature in a K10ST

150 tensiometer (Krüss GmbH, Hamburg, Germany). Electrical conductivity was determined in a

151 conductivity meter LF 323 (WTW GmbH, Weilheim, Germany) at $25^{\circ} \mathrm{C}$. All determinations were

152 performed in triplicate.

\section{$153 \quad$ 2.3.2 Droplet size distribution}

154 Droplet sizes were measured by laser diffraction in a Mastersizer 2000 (Malvern Instruments, Ltd.,

155 Worcestershire, UK). Solutions were diluted in recirculating water (3000 rpm), until it reached an 
obscuration of $12 \%$. The refractive indices of sunflower oil (1.469) and water (1.330) were used as

157 particle and dispersant, respectively. Measurements were made in triplicate after production.

158

159

160

161

162

163

164

165

166

167

168

169

170

171

172

173

174

175

176

177

178

179

180

\subsubsection{Oxidative stability}

For lipid oxidation measurements, immediately after production, biopolymers solutions (15 wt.\% pullulan, $30 \mathrm{wt} . \%$ dextran70, $20 \mathrm{wt} . \%$ dextran500 and $30 \mathrm{wt} . \% \mathrm{WPC}$ ) containing emulsified fish oil were stored in $100 \mathrm{~mL}$ brown bottles at $40{ }^{\circ} \mathrm{C}$ in the dark for 14 days. Each bottle contained $40 \mathrm{~g}$ of solution. Emulsified fish oil (10 wt.\% fish oil-in-water emulsion; stabilized with $1 \mathrm{wt} \%$ WPI) was also analyzed. Samples were taken at day 0, 4, 9 and 14 for analysis.

\subsubsection{Determination of peroxide value and tocopherol content}

Lipids were extracted from solutions according to Bligh and Dyer method using a reduced amount of the chloroform/methanol (1:1, wt.\%) solvent (Bligh \& Dyer, 1959). Two extractions were made from each sample. Peroxide value was determined on lipid extracts using the colorimetric ferric-thiocyanate method at $500 \mathrm{~nm}$ as described by Shantha and Decker (1994). For tocopherol determination, lipid extracts (1-2 g) were weighed off and evaporated under nitrogen and re-dissolved in heptane prior to analysis according to AOCS (1998).

\subsubsection{Secondary oxidation products - Dynamic headspace GC-MS}

Approximately $4 \mathrm{~g}$ of solutions and $30 \mathrm{mg}$ internal standard (4-methyl-1-pentanol, $30 \mu \mathrm{g} / \mathrm{g}$ water) were weighted out in a $100 \mathrm{~mL}$ purge bottle, to which $5 \mathrm{~mL}$ of distilled water and $1 \mathrm{~mL}$ antifoam (Synperonic $800 \mu \mathrm{L} / \mathrm{L}$ water) were added. The bottle was heated to $45^{\circ} \mathrm{C}$ in a water bath while purging with nitrogen (flow $150 \mathrm{~mL} / \mathrm{min}, 30 \mathrm{~min}$ ). Volatile secondary oxidation products were trapped on Tenax GR tubes. The volatiles were desorbed again by heating $\left(200^{\circ} \mathrm{C}\right)$ in an Automatic Thermal Desorber (ATD-400, Perkin Elmer, Norwalk, CN), cryofocused on a cold trap $\left(-30^{\circ} \mathrm{C}\right)$, released again $\left(220^{\circ} \mathrm{C}\right)$, and led to a gas chromatograph (HP 5890IIA, Hewlett Packard, Palo Alto, CA, USA; Column: DB-1701, $30 \mathrm{~m}$ x $0.25 \mathrm{~mm}$ x $1.0 \mu \mathrm{m}$; J\&W Scientific, CA, USA). The oven program had an initial temperature of $45^{\circ} \mathrm{C}$ for $5 \mathrm{~min}$, increasing with $1.5^{\circ} \mathrm{C} / \mathrm{min}$ until $55^{\circ} \mathrm{C}$, with $2.5^{\circ} \mathrm{C} / \mathrm{min}$ until 
$18190^{\circ} \mathrm{C}$, and with $12.0^{\circ} \mathrm{C} / \mathrm{min}$ until $220^{\circ} \mathrm{C}$, where the temperature was kept for $4 \mathrm{~min}$. The individual

182 compounds were analyzed by mass-spectrometry (HP 5972 mass-selective detector, Agilent

183 Technologies, USA; electron ionization mode, $70 \mathrm{eV}$; mass to charge ratio scan between 30 and 250).

184 Emulsified fish oil (10 wt.\% oil-in-water emulsion, stabilized with 1 wt.\% WPI) was also analyzed

185 following the same procedure. The individual compounds were identified by both MS-library searches

186 (Wiley 138 K, John Wiley and Sons, Hewlett-Packard) and by authentic external standard and

187 quantified through calibration curves. The external standards employed were 2-ethylfuran, 1-penten-3-

188 one, 1-penten-3-ol, (E)-2-pentenal, hexanal, (E)-2-hexenal, (E,E)-2,4-heptadienal, $(E, Z)-2,6-$

189 nonadienal and (E)-2-decenal (Sigma-Aldrich, Brøndby, Denmark).

$190 \quad 2.4$ Electrohydrodynamic process

191 In lab scale, the electrohydrodynamic process was carried out by adding the biopolymer solutions

192 containing the fish oil to a syringe which was placed in a syringe pump (New Era Pump Systems, Inc.,

193 USA). The syringe pump delivered solutions with a flow rate of $0.01 \mathrm{ml} / \mathrm{min}$. A $16 \mathrm{G}$ needle (Proto

194 Advantage, Canada) was used. Using a high voltage power supply (Gamma High Voltage Research,

195 USA), an electric field of $20 \mathrm{kV}$ was applied between the spinneret of the syringe and a $15 \times 15 \mathrm{~cm}$

196 collector plate made of stainless steel with alumina foil wrapped around it. The distance between the

197 syringe tip and the collector plate was $15 \mathrm{~cm}$. The electrospinning process was conducted at room

198 temperature. NMS were produced in batches during 30 and 120 min under nitrogen atmosphere. A

199 schematic diagram of the lab facilities used for electrospinning and electrospraying processes is shown

200 in the Supplementary Material (Fig. S1).

201 Selected solutions were tested for production of NMS in pilot-plant scale. For that purpose, Fluidnatek

202 LE-100 (Bioinicia and Fluidnatedk®, Valencia, Spain) was employed. NMS were produced at room

203 temperature in batches during 10 min by using 24 needles with an inner diameter of $0.6 \mathrm{~mm}$. Pullulan

204 solutions were processed at a flow rate of $5 \mathrm{~mL} / \mathrm{h}$ by applying an electric field of $35 \mathrm{kV}$ between the

205 needles and the collector, which were placed at $15 \mathrm{~cm}$ distance. In the case of dextran solutions, an

206 electric field of $42 \mathrm{kV}$ was applied and the distance used between the needles and the collector was 10 
$\mathrm{cm}$. Different processing conditions were used in lab and pilot-plant scales since the pilot-plant scale equipment allowed to apply a higher voltage when compared to the voltage source used in lab scale. This allowed to obtain a stable Taylor cone (at least for pullulan solutions) at higher flowrates when using the pilot-plant equipment, which is desirable to increase the productivity of the process.

\subsection{Characterization of NMS}

\section{$212 \quad$ 2.5.1 Morphology}

213 The morphology of the NMS for the different biopolymers concentrations was investigated using 214 scanning electron microscopy (SEM) (FEI Inspect, Hillsboro, OR, USA). Approximately $0.5 \times 0.5 \mathrm{~cm}$ 215 of the NMS sheet was placed on carbon tape and sputter coated with gold, $10 \mathrm{~s}, 40 \mathrm{~mA}$ utilizing a 216 Cressington 208HR Sputter Coater (Cressington Scientific Instruments, Watford, England).

Selected NMS were cut udner liquid nitrogen and imaged in an FEI Helios dual beam scanning 218 electron microscope in high vacuum at room temperature by monitoring the secondary electrons with the Through-The-Lens detector. No sample coating was used, instead the charge balance approach was used. The fiber diameter and the bead size were determined from the micrographs by using the open source image processing program ImageJ (National Institutes of Health). One hundred random fibers were measured at 10 different points and all the beads, if presented. The number beads/area was measured on all the micrographs presenting beads.

\subsubsection{Lipid encapsulation and distribution}

225 Fourier transform infrared (FT-IR) analysis was carried out in order to detect the presence of fish oil in selected NMS. Transmission FT-IR experiments of control NMS (containing biopolymer and Tween20) and NMS with emulsified and neat oil were recorded in a controlled chamber at $21^{\circ} \mathrm{C}$ with a FT-IR Tensor 37 equipment (Bruker, Germany). Samples of $2 \mathrm{mg}$ of NMS were gently mixed and dispersed in $120 \mathrm{mg}$ of spectroscopic grade $\mathrm{KBr}$. The $\mathrm{KBr}$ pellets were prepared by first milling the $\mathrm{KBr}$ and then adding the encapsulated powder into the milled $\mathrm{KBr}$ with gentle mixing. It allowed to 231 retain the existing composition of the encapsulates when entrapped in the pellet. Attenuated total 
233

coupling the ATR accessory GoldenGate of Specac Ltd. (Orpington, UK) to the above-mentioned FT-

234 IR equipment. All spectra were recorded within the wavenumber range of $4000-600 \mathrm{~cm}^{-1}$ by averaging 23520 scans at $4 \mathrm{~cm}^{-1}$ resolution.

236 Encapsulation efficiency (EE) of selected NMS was determined by measuring the non-entrapped fish 237 oil according to Moomand and Lim (2014) with some modifications. NMS (50 mg) were submerged 238 in heptane $(10 \mathrm{~mL})$ and gently shaken $(100 \mathrm{rpm})$ for $15 \mathrm{~min}$. The mixture was filtered and the 239 absorbance of the liquid was measured at $250 \mathrm{~nm}$ (UV-1800, Shimadzu, Japan). The amount of oil 240 present in the liquid was determined from a calibration curve $\left(\mathrm{R}^{2}=0.99\right)$, prepared by dissolving 241 various quantities of fish oil in heptane. The EE was calculated as:

$$
E E(\%)=\frac{A-B}{A} * 100
$$

where $\mathrm{A}$ is the total theoretical amount of fish oil and B is the free amount of fish oil in the collection 244 solution. Measurements were carried out in triplicate.

245 The lipid distribution of selected NMS was investigated by cutting them under liquid nitrogen and 246 imaging their cross-sections with the FEI Helios dual beam scanning electron microscope, as 247 described above. Furthermore, wet-scanning tramission electron microscopy in environmental SEM 248 mode was also carried out using a FEI Quanta 200F FEG for selected NMS in order to determine the 249 lipid distribution in the ultrathin fibers.

\subsubsection{Oxidative stability}

251 After production, analyses of PV and secondary oxidation products of selected NMS were carried out. 252 Lipids were extracted from NMS according to Bligh and Dyer method and PV determined as 253 previously described. Secondary oxidation products were also measured as described above, using 100 $254 \mathrm{mg}$ of NMS in each bottle, which was purged with nitrogen (flow $240 \mathrm{~mL} / \mathrm{min}, 30 \mathrm{~min}$ ). The external 255 standards employed were 2-ethylfuran, 1-penten-3-one, 1-penten-3-ol, $(E)$-2-pentenal, hexanal, $(E)-2$ 256 hexenal, (E,E)-2,4-heptadienal, octanal and nonanal (Sigma-Aldrich, Brøndby, Denmark). 


\subsection{Statistical analysis}

258

259

260

261

262

263

264

265

266

267

268

269

270

271

272

273

274

275

276

277

278

279

280

281

282

Statgraphics Centurion XV (Statistical Graphics Corp., Rockville, MD, USA) was used for data analysis. Data were expressed as mean \pm standard deviation. Firstly, multiple sample comparison analysis was performed to identify significant differences between samples. Secondly, mean values were compared by using the Tukey's test. Differences between means were considered significant at $\mathrm{p}$ $<0.05$.

\section{RESULTS AND DISCUSSION}

\subsection{Solutions properties and morphology of NMS}

Solution properties such as viscosity, surface tension and conductivity, which are critical for the success of electrohydrodynamic processing, are shown in Table 1 . These physical properties, which are mainly dependent on the type of solvent, polymer molecular weight and concentration, affected the morphology of the nano-microstructures obtained (Fig. 1). A particularly important parameter is viscosity, which can be used as an indication of the degree of polymer chain entanglements in the solution (Weiss et al., 2012). As expected, viscosity increased with increasing biopolymer concentration for all solutions; for pullulan, dextran70, and dextran500 a considerable increase in viscosity was observed when increasing the concentration from 5, 20 and 10 wt.\% to 15,40 and 30 wt.\%, respectively (Table 1). It should be noted that dextran500 solutions showed a considerably higher viscosity when compared to dextran70 solutions at the same concentration, which is explained by the higher molecular weight of dextran500. Looking at the morphology of the corresponding NMS, it is evident that the increase in viscosity was associated with formation of fibers instead of capsules (Fig. 1C, 1F, 1I). This is in line with the results found by Stijnman, Bodnar, \& Hans Tromp. (2011) who reported fiber formation from $15 \mathrm{wt} \%$ aqueous solutions of pullulan $200 \mathrm{kDa}$. Similar to our results, Ritcharoen et al. (2008) also reported the production of fibers from 40-55 wt.\% aqueous solutions of dextran $70 \mathrm{kDa}$. It is worth mentioning that for dextran70 (40 wt.\%) and dextran500 (30 wt.\%), the fibers contained large amounts of beads (Fig. 1F, I). The presence of beads was not due to the surface tension of these solutions when compared to pullulan solution (15 wt.\%) (Table 1). 
Dextran500 and specially dextran70 solutions had lower surface tension than pullulan solutions, which

\section{4}

285

286

should have allowed the electric forces to overcome the surface tension to initiate the jet more easily resulting in the formation of fiber with less beads defects (Chronakis, 2010). This was not observed, suggesting that the formation of beaded fibers for dextran70 and dextran500 might be related to differences in chain entanglements exhibited by these polymers when compared to pullulan (even at similar values of viscosity). The decrease in surface tension for dextran70 solutions when increasing concentration was remarkable, indicating emulsifying properties for this polymer. In terms of conductivity, dextran500 solutions showed considerably higher values when compared to pullulan and dextran70 (Table 1). This might be most likely to their different ash content: $1.0 \mathrm{wt} \%$ for dextran500 and no more than $0.1 \mathrm{wt} . \%$ for dextran70 and pullulan (data on ash content were provided by the suppliers). Conductive polymer solutions will favor the production of more uniform fibers due to an increase of mutual charge repulsion within the jet leading to a further elongation of the jet (Ramakrishna, 2005). However, in highly conductive solutions, such as dextran500 solutions, the effective repulsion force for stretching the fiber is reduced due to sliding of excess charge along the surface of the polymer jet; this can lead to irregular electrospun materials (Lim, 2015).

WPC exhibited poor NMS-forming properties, requiring high polymer concentration in order to have sufficient chain entanglement (Table 1). Even though it was possible to form capsules from WPC (Fig. $1 \mathrm{~K}, \mathrm{~L})$, a large amount of irregular morphologies was observed during production of the particles. The irregular morphologies may be overcome by adding a surfactant (e.g. Tween-20) to the electrospinning solution, which reduces the surface tension of the WPC-water solution, thus improving the sprayability (Pérez-Masiá et al., 2015; Gómez-Mascaraque et al., 2016b). Contrarily, dextran, both 70 and $500 \mathrm{kDa}$, led to the formation of spherical capsules at $20 \mathrm{wt} . \%$ concentration of polymer (Fig. 1D, H). Similarly, capsules of dextran $70 \mathrm{kDa}$ containing lycopene were also reported by Pérez-Masiá et al. (2015). Solution of 25 wt.\% dextran70 also led to capsules, allowing an increase in the production rate of NMS when compared to the $20 \mathrm{wt} \%$ dextran70 solution. For dextran500, capsules with fibril defects were observed at $20 \mathrm{wt} \%$ due to its higher molecular weight which favored more polymer chain interactions (Fig. 1H). 


\subsection{Droplet size distribution and oxidative stability of solutions}

311 The distribution of the lipids in the biopolymer solutions has a great influence on the lipid entrapment

312 and distribution in the final NMS (García-Moreno et al., 2016). Moreover, it may affect the oxidative

313 stability of the solutions during storage due to differences in the surface area. Therefore, the effect of

314 blending the emulsified oil with the biopolymer solutions on the droplet size distribution was

315 evaluated. It was observed that the addition of pullulan and dextran70 did not modify the droplet size

316 distribution of the parent emulsion $\left(D_{3,2}=134 \pm 1 \mathrm{~nm}\right)$. On the other hand, dextran500 and WPC

317 solutions had significantly larger droplets when compared to the parent emulsion; with $\mathrm{D}_{3,2}=270 \pm 1 \mathrm{~nm}$

318 and $D_{3,2}=207 \pm 5 \mathrm{~nm}$, respectively (see Fig. $\mathrm{S} 2$ of the Supplementary Material). This could be attributed

319 to the presence of non-adsorbed biopolymers in the continuous phase which are capable of promoting

320 droplet flocculation through a depletion mechanism. Unadsorbed biopolymers can promote association

321 of oil droplets by inducing an osmotic pressure gradient within the continuous phase surrounding the

322 droplets (Singh \& Ye, 2009). For each biopolymer, this phenomenon occurs above a critical

323 flocculation concentration, which is dependent on the effective volume of the biopolymer in aqueous

324 solution (Chanamai \& McClements, 2001). This explains the differences observed between dextran70

325 and dextran500, having the latter a higher effective volume.

326 The oxidative stability of biopolymer solutions containing emulsified fish oil was investigated in order

327 to determine the effect of each biopolymer on fish oil oxidation (e.g. anti- or prooxidant). Fig. 2 shows

328 the content of primary oxidation products (e.g. hydroperoxides) in biopolymer solutions during

329 storage. A lag phase of four days was observed for the emulsion without any biopolymer (control),

330 followed by a significant increase in PV during the rest of the storage period (up to $7.6 \pm 0.1 \mathrm{meqO} \mathrm{O}_{2} / \mathrm{kg}$

331 oil at day 14). Dextran70 and WPC exhibited an antioxidant effect $\left(\mathrm{PV}<5 \mathrm{meqO}_{2} / \mathrm{kg}\right.$ oil), with

332 dextran70 solution resulting in a longer lag phase (9 days) and WPC solution maintaining the initial

333 low PV. On the contrary, pullulan and dextran500 solutions did not show any lag phase and both

334 polysaccharides thus exhibited a prooxidant effect on lipid oxidation (Fig. 2). These results correlated

335 well with the $\alpha$-tocopherol content of the solutions after storage. Thus, dextran70 and WPC solutions

336 had a lower consumption of this endogenous antioxidant when compared to pullulan and dextran500 
(see Fig. S3 of the Supplementary Material). Likewise, pullulan solutions had the highest content of 338 secondary oxidation products (Fig. 3a-d), followed by dextran500 solutions when considering 2ethylfuran and (E,E)-2,4-heptadienal volatiles (Fig. 3a, d). Dextran70 and WPC solutions had a lower content of volatiles than pullulan and dextran500 solutions, apart from 1-penten-3-ol and (E)-2hexenal where dextran70 and WPC solutions were the second most oxidized, respectively (Fig. 3).

342 The low lipid oxidation observed for solutions containing WPC is explained by the recognized antioxidant properties of whey protein such as chelation of transition metals by lactoferrin and free radicals scavenging by amino acids containing sulfhydryl groups (e.g. cysteine) (Tong, Sasaki, McClements, \& Decker, 2000). The protection effect of dextran70, which was not observed for dextran500, may be related to the differences observed in the droplet size distribution of the solutions. Dextran500 solution showed flocculation and/or coalescence, which may change the interface and thereby making the oil more accessible to prooxidants. Moreover, the surface activity of dextran70

349 (Table 1), may allow the incorporation of this polysaccharide (which is in excess in the solution) to the interface of the oil droplets, increasing the protection of the lipids. Similarly, this mechanism was also proposed by Matsumura et al. (2003) in order to explain the antioxidant effect of gum arabic and a 352 soluble soybean polysaccharide in oil-in-water emulsions stabilized with $\beta$-casein. These authors also found a prooxidant behavior of pullulan in oil-in-water emulsions, both on the formation of hydroperoxides and secondary oxidation products (e.g. malondialdehyde). Contrary to other complex polysaccharides having protein moieties (e.g. gum arabic), pullulan did not show free radical scavenging activity (Matsumara et al., 2003). Moreover, it did not present surface activity (Table 1), which could have led to an interface with improved properties. The absence of these properties, together with the fact that pullulan had a higher content of metals $(130 \mathrm{ppm})$, which catalyze lipid oxidation, when compared to WPC and dextran70 $(<2 \mathrm{ppm})$ might be the reason for the lower 


\subsection{Characterization of selected NMS: emulsified vs. neat oil}

362 As a consequence of the satisfactory results obtained on the morphology of the NMS and on the

363 droplet size distribution of the biopolymers solutions, 15 wt.\% pullulan and 25 wt.\% dextran70

364 solutions were chosen for fiber- and particle-based lipid encapsulation, respectively. Moreover, the 365 protective effect of dextran70 against lipid oxidation in solution supported this selection. Although 366 pullulan exhibited a prooxidant effect in solution, it may protect the oil when obtaining dried encapsulates (e.g. fibers) due to its inherent properties as a barrier for oxygen (Bakry et al., 2016). Nonetheless, it is worth mentioning that, due to the high solubility of pullulan in water which negatively affects to its oxygen barrier properties, pullulan fibers containing fish oil should only be considered to be used as omega-3 delivery systems in dry food products. Contrary to the properties of electrosprayed nano-microcapsules, the dimensional and morphological nature of electrospun nanomicrofibers (e.g. continuous in length) has limited their application in food, except for their use in bioactive packaging strategies (Lopes da Silva, 2012). Therefore, further research is needed to explore the encapsulating potential of electrospun fibers in food and one interesting possibility could be their incorporation into multi-layered food systems. For instance, fish oil-loaded pullulan fibers may be successfully incorporated in multi-layered granola bars, but this requires further evaluation.

\subsubsection{Morphology}

378 The three types of pullulan nano-microfibers produced at lab scale presentend circular cross-sections, which were filled up either with pullulan and/or fish oil (Fig. 4-c). Nevertheless, differences in morphology were observed for pullulan fibers containing emulsified oil compared to fibers with neat oil and control pullulan fibers (with no added oil). Fibers containing neat oil presented the largest 382 diameter (75\% of fibers with diameter between 800 and $1100 \mathrm{~nm}$ ), followed by fibers with emulsified oil ( $83 \%$ of fibers with diameter between 600 and $800 \mathrm{~nm})$ and control fibers $(80 \%$ of fibers with

384 diameter between 500 and $700 \mathrm{~nm}$ ) (Fig. 4d). The larger diameter of the fibers containing fish oil compared to the control ones can be explained by an increase in solution viscosity due to the addition of fish oil; from $878.0 \pm 0.4 \mathrm{cP}$ for the control solution to $1010.0 \pm 16.0$ and $1040.0 \pm 26.0 \mathrm{cP}$ for the 
Moomand and Lim (2015) reported an increase in fiber diameter when augmenting fish oil load in

PVA and zein fibers, respectively. Nevertheless, these authors obtained fibers with smaller diameters;

95\% of PVA fibers were between 100-150 nm and $90 \%$ of zein fibers were between 100-400 nm. For

fibers containing neat oil, the supplementary addition of Tween20, which led to an increase in the lipid

content (up to $12 \mathrm{wt} . \%$ ), might be responsible for the larger diameter of this type of fibers when

compared to fibers containing emulsified oil. Moreover, fibers with neat oil exhibited the poorest

thickness uniformity since they had the broadest diameter distribution (Fig. 4d) and the largest

standard deviation from the fiber average diameter (Fig. 4e). In addition, fibers with emulsified oil

presented aproximately 14 times less bead-defects than fibers with neat oil (47 beads/14,612 $\mu \mathrm{m}^{2}$

versus 100 beads $/ 2,281 \mu \mathrm{m}^{2}$ ). It has to be mentioned that these are relative numbers as they represent

the visualized areas which are prone to have artefacts caused by sample inhomogeneity and/or sample

preparation (e.g. transfer and cutting). In any case, the size of the beads for fibers with neat oil were

considerably larger (Fig. 4f). This cannot be attributed to differences in viscosity, since both solutions

(with emulsified and neat oil) contained the same concentration of pullulan and fish oil which are the

main factors determining viscosity. It can neither be explained by a superior surface tension value of

the solution with neat oil, since that solution contained Tween 20 which favors jetting and avoids the

formation of beads (Pérez-Masiá, Lagaron, \& Lopez-Rubio, 2014). However, these differences in

morphology may be attributable to a different distribution of fish oil in the two solutions. Emulsified

oil was homogenized in a high-pressure homogenizer before mixing with pullulan, leading to a very

fine emulsion $(\mathrm{D}[0.5]=162 \pm 1 \mathrm{~nm})$. On the other hand, neat oil was added to the pullulan solution containing Tween20 and mixed mechanically, which led to a final coarse emulsion $(\mathrm{D}[0.5]=2748 \pm 1$ nm). As a consequence, the large droplets presented in the neat oil solution could not be incorporated inside the fibers resulting in large bead structures. Similar observations were reported by GarcíaMoreno et al. (2016) and Arecchi, Mannino, \& Weiss (2010) in PVA fibers when increasing the load 412 of emulsified fish oil and emulsified hexadecane, respectively. Likewise, production of pullulan fibers with emulsified or neat oil at pilot-plant scale led to the same differences in morphology, although the 
415 of the Supplementary Material). Although the higher flowrate employed in pilot-plant scale could

416 have favored an increase in fiber diameter, the superior voltage used causes greater stretching of the

417 solution by increasing the electrostatic repulsive force which ultimately led to a reduction in the fiber

418 diameter (Bhardwaj \& Kundu, 2010).

419 Fig. 5 shows the morphology of the three types of dextran capsules produced at lab scale; without oil 420 (Fig. 5a), with emulsified (Fig. 5b) and neat oil (Fig. 5c). In general, the particles obtained were 421 almost spheres with an opened part such as a toroid shape (marked by arrows in Fig. 5). They also 422 presented a broad size distribution including both small $(<300 \mathrm{~nm})$ and large $(>1000 \mathrm{~nm})$ capsules. 423 These observations are in line with the results reported by Pérez-Masiá et al. (2015) for dextran 424 capsules containing a mixture of soybean oil and lycopene, and by Gómez-Mascaraque and LópezRubio (2016) for gelatin, SPI and WPC capsules containing $\alpha$-linolenic acid. It is also worth noting that dextran capsules containing neat oil had a broader size distribution with larger diameters $(>3000$ $\mathrm{nm}$ ) than dextran particles with emulsified oil (Fig. 5d). This may be attributed to differences in the droplet size distribution of the dextran solutions containing emulsified (fine emulsion) or neat oil (coarse emulsion). This is in agreement with the findings of Gómez-Mascaraque and López-Rubio (2016) who reported that the emulsification process, which determines the size of the oil droplets, had an important influence on the size of the electrosprayed capsules. These authors observed that capsules with a lower diameter were obtained when employing an intense homogenization process (e.g. UltraTurrax followed by ultrasounds), which resulted in smaller oil droplets when compared to the use of a 434 less intense emulsification treatment (e.g. only Ultra-Turrax). Similar morphologies, than the ones 435 previously described, were found for dextran capsules produced at pilot-plant scale (Fig. S5 of the 436 Supplementary Material). Similar to pullulan fibers, both types of capsules obtained in pilot-plant scale (with emulsified and neat oil) presented a reduced size when compared to the ones obtained in 438 lab scale. This was also most likely due to the superior voltage employed in pilot-plant scale which 439 increased the electrostatic repulsive force favoring the disruption of the droplets (Ghorani \& Tucker, 440 2015). 


\subsubsection{Lipid encapsulation and distribution}

442 To verify that fish oil was not completely degraded durin the electrohydrodynamic processing, FTIR

443 analysis was carried out. For that purpose, the characteristic bands of fish oil not overlapping with the

444 infrared bands of the encapsulating biopolymers (e.g. pullulan and dextran) were identified. Fig. 6

445 shows ATR-FTIR spectra of fish oil, control NMS without fish oil (e.g. only biopolymer and Tween

446 20), and NMS with emulsified or neat oil. It was found that many of the characteristic bands of fish oil

447 overlapped with infrared bands of pullulan, dextran or both; which did not allow to identify potential

448 interactions between the polymers and the oil. Nevertheless, the following differences (marked by

449 arrows in Fig. 6a-b) between the control NMS and NMS containing fish oil were observed: i)

450 characteristic bands for functional groups of alkanes, attributed to $\mathrm{C}-\mathrm{H}$ stretching vibrations, with

451 wavenumbers $3000-2700 \mathrm{~cm}^{-1}$, particularly a band at $2854 \mathrm{~cm}^{-1}$ corresponding with $-\mathrm{C}-\mathrm{H}\left(\mathrm{CH}_{2}\right.$ and

$452 \mathrm{CH}_{3}$ groups, symmetrical stretching); and ii) a band at $1746 \mathrm{~cm}^{-1}$ corresponding to the $-\mathrm{C}=\mathrm{O}$ group of

453 triglycerides (ester stretching) (Guillén \& Cabo, 1998; Hamilton \& Cast, 1999). Thus, the presence of

454 fish oil in the NMS was confirmed by the appearance of these two characteristics bands of fish oil.

455 Likewise, these infrared bands were selected by Pérez-Masiá et al. (2015) to confirm the presence of

456 soybean and lycopene in dextran capsules. It should be mentioned that the intensity of these bands

457 were similar for both pullulan fibers with emulsified and neat oil (Fig. 6a), but differences were

458 observed between the dextran capsules (Fig. 6b). Dextran capsules with neat oil showed a lower

459 intensity for the two bands, indicating that less oil was incorporated or that the oil was degraded

460 during the process. The decreased oil content could be due to an observed phase separation for the

461 dextran solution containing neat oil during the electrospraying process, further commented below.

462 The methodology selected to incorporate the fish oil to the polymer solution had a statistically

463 significant influence on the EE values obtained. For both types of biopolymers (pullulan and dextran),

464 incorporating the oil as emulsified oil led to lower values of EE $(69.1 \pm 0.2$ and $68.3 \pm 0.3 \%$,

465 respectively) when compared to the EE obtained when adding neat oil $(89.6 \pm 0.7$ and $75.5 \pm 0.9$,

466 respectively). It is of great importance to obtain high EE values when working with omega-3 PUFA,

467 since the encapsulation affects the exposure of the bioactive compound to prooxidants (e.g. oxygen, 
light, free radicals, metal ions), both during storage of the NMS and when incorporated into food systems. Apart from the EE value of pullulan fibers containing neat oil, the EE values obtained in this study are considerably lower than those reported by Moomand and Lim (2014) for zein fibers loaded with fish oil $(91.2 \pm 1.1 \%)$. The presence of surface oil was also supported by the wet-STEM in ESEM image shown in Fig. 7a. For pullulan fibers, both encapsulated and non-entrapped oil droplets could be differentiated (blue and red arrows in Fig. 7a, respectively). Small particles sitting on the fibers, which could indicate the presence of surface oil, were also observed in the cryo-SEM images of the fibers (marked by white arrows in Fig. 4b-c). These small features in the surface of the fibers were more abundant in fibers containing emulsified than neat oil; which correlated well with the EE values. This might be related to the fact that in fibers with neat oil the lipids were mostly located in beads, which minimized the specific surface area and thereby reducing the interactions with the solvent used to extract the surface oil in the analysis. For dextran particles, Fig. $7 b$ shows a capsule with a dense core and small darker circles (marked with blue arrows) which are attributed to the presence of either small dextran particles or oil droplets sitting inside the capsules. These areas with higher constrast appear blurred in all our micrographs indicating that these small dextran particles or oil droplets are placed in the interior of the dextran capsule. Staining the NMS with $\mathrm{OsO}_{4}$ was not selective for the lipids, and therefore did not help locating the presence of encapsulated or surface oil in neither dextran particles nor pullulan fibers (see Fig. S6 of the Supplementary Material).

\subsubsection{Oxidative stability}

Table 2 shows the content of hydroperoxides and selected secondary oxidation products (e.g. 1penten-3-ol, hexanal and nonanal) of pullulan fibers and dextran particles right after their production. For pullulan fibers, the methodology used to add the oil to the electrospinning solution (emulsified or neat) had a great influence on the oxidative status of the fibers. In lab scale, it was found that fibers containing neat fish oil presented a significantly lower PV than fibers with emulsified oil when running batches of 120 and $30 \mathrm{~min}$. The same trend was found for the content of the fibers in 1penten-3-ol, a volatile product derived from the oxidation of omega-3 fatty acids. This correlated well with the lower EE values obtained for fibers with emulsified oil, implying more surface oil which is 
495

496

497

498

499

500

501

502

503

504

505

506

507

508

509

510

511

512

513

514

515

516

517

518

519

520

unprotected against prooxidants. These results are in accordance with the higher oxidative stability obtained for zein fibers loaded with fish oil when increasing fish oil entrapment from 91.2 to $95.9 \%$ (Moomand \& Lim, 2014). Furthermore, the larger beaded structures present in the fibers with neat oil, where the oil is mainly located, may have led to a greater protection of fish oil against oxidation than in fibers with emulsified oil presenting smaller droplets which increases the specific surface area. Similarly, Moomand and Lim (2014) reported a higher oxidative stability for isopropanol-based zein fibers, having large beads, when compared to beadless ethanol fibers due to its smaller surface-tovolume ratio. Besides, incorporating the oil as neat oil avoided lipid oxidation happening during the homogenization process required to produce the emulsified oil (Serfert, Drusch, \& Schwarz, 2009). Additionally, decreasing the duration of the production batch from 120 to $30 \mathrm{~min}$, which reduces the exposure of the surface oil, decreased significantly the PV of fibers both with emulsified and neat oil and the content of 1-penten-3-ol for fibers with emulsified oil (Table 2). Likewise, fiber production at pilot-plant scale, which implied shorter batches $(10 \mathrm{~min})$, led to significantly less oxidation of fibers with emulsified oil when compared to production at lab scale; whereas no significant differences were found for fibers with neat oil in terms of PV and volatiles. Therefore, pullulan fibers containing neat oil and produced at lab scale in batches of 30 min exhibited the lowest oxidation after production, with the lowest PV $\left(12.3 \pm 0.9 \mathrm{meq} \mathrm{O}_{2} / \mathrm{kg}\right)$ and the lowest content of 1 -penten-3-ol $(15.5 \pm 5.1 \mathrm{ng} / \mathrm{g})$. Nonetheless, it is worth mentioning that pullulan fibers evaluated in this study had a high content of other volatiles such as hexanal and nonanal, which are derived from oxidation of omega-6 and omega9 fatty acids, respectively. Although the concentration of these volatiles increased with the duration of the production time, they were also present in the control sample (only containing pullulan and Tween20). This indicated that they were already present in the biopolymer or they were obtained as consequence of degradation of pullulan, as concluded from the volatiles analysis of pullulan fibers not containing Tween20 (unpublished data). In any case, these results denoted a superior oxidative stability of pullulan fibers containing neat oil when compared to other fibers produced using other polymers such as PVA (García-Moreno et al., 2016). 
521 Electrosprayed dextran capsules containing emulsified oil showed a low oxidative stability (PV >40

522 meq $\mathrm{O}_{2} / \mathrm{kg}$ ) after production both in lab and pilot-plant scales (Table 2). This might be attributed to the

523 opened-part of the capsules which could allow the leaking of oil from the dextran matrix and it may

524 also be attributed to the presence of surface oil. Even though the duration of the batch production was

525 reduced from 120 to $10 \mathrm{~min}$, production in pilot-plant scale led to a higher content of PV and volatiles

526 when compared to lab scale. This is explained by the presence of droplets in the collector, as a

527 consequence of the lack of optimization of the solution for working in the vertical configuration of the

528 pilot-plant equipment. Contrary to pullulan fibers, the addition of neat fish oil instead of emulsified

529 did not enhance lipid protection. Although the volatiles content was reduced when working in lab

530 scale with a horizontal configuration, a high PV (>40 meq $\mathrm{O}_{2} / \mathrm{kg}$ ) with a large standard deviation was

531 still obtained. This may be due to the fact that the solution was not stable during the electrospraying

532 process, experiencing phase separation which led to capsules with not homogenous composition (lipid

533 content of $7.7 \pm 3.4 \mathrm{wt} . \%$ instead of the theoretical $12.0 \mathrm{wt} . \%$ ). In pilot-plant scale, a significantly lower

$534 \mathrm{PV}\left(21.2 \pm 9.5\right.$ meq $\left.\mathrm{O}_{2} / \mathrm{kg}\right)$ was obtained for capsules with neat oil when compared to capsules with

535 emulsified oil. However, the phase separation of the dextran solution contained neat oil was even more

536 severe in pilot-plant scale, probably due to the long tube connecting the syringe and the needles and to

537 the vertical configuration, leading to capsules with a lipid content of $2.1 \pm 0.2$ wt.\%. These results

538 indicated that future studies are required in order to: i) produce physically stable dextran solutions

539 containing neat fish oil (e.g. using Ultraturrax and/or high pressure homogenizers), and ii) optimize

540 solutions composition and electrospraying processing variables (flowrate, voltage and distance) which

541 allow to only obtain fine particles in the collector (e.g. no droplets). Similarly to our results, Gómez-

542 Mascaraque and López-Rubio (2016) reported a low protection of $\alpha$-linolenic acid when encapsulated

543 in gelatin capsules by electrospraying, even when capsules with an appropriate morphology were

544 obtained. 
545

546

547

548

549

550

551

552

553

554

555

556

557

558

559

560

561

562

563

564

565

566

567

568

569

570

\section{CONCLUSIONS}

Carbohydrate-based NMS containing fish oil were successfully obtained by using pullulan and dextran. Pullulan (15 wt.\%) and dextran $70 \mathrm{kDa}(25 \mathrm{wt} . \%)$ solutions presented adequate properties to allow the formation by electrohydrodyanmic processing of nano-microfibers and nano-microcapsules, respectively. Dextran particles showed a low oxidative stability both when adding the oil as emulsified or neat oil in lab and pilot-plant scale. The low oxidative stability may be attributed to a poor interaction between the polymer and the fish oil which led to phase separation of the electrospraying solution, capsules with an opened-part and oil on the surface. On the other hand, pullulan fibers with neat oil produced in small batches (30 or $10 \mathrm{~min}$ at lab or pilot-plant scale, respectively) exhibited a superior oxidative stability after production, compared to fibers containing emulsified oil. The superior oxidative stability of fibers with neat oil was most likely due to a high EE (89.6 \pm 0.7$)$, due to the location of fish oil in bead-structures which implied a lower specific surface area, and due to the elimination of the homogenization process. These promising results may open-up new oportunities for the utilization of pullulan as biopolymer for encapsulation of omega-3 PUFA and other heat-sentive bioactives by electrospinning.

\section{ACKNOWLEDGEMENTS}

This work was supported by the European Commission (ELECTRONANOMEGA project). P.J. García-Moreno acknowledges a Marie-Curie postdoctoral fellowship (Grant Agreement 654818). J.M. Lagaron would like to thank the Spanish Ministry of Economy and Competitiveness (MINECO) project AGL2015-63855-C2-1-R for financial support. The authors are also grateful to Dr. Celia Libran from Bioinicia S.L. for experimental support with the electrospinning equipment in pilot-plant scale.

\section{REFERENCES}

Aceituno-Medina, M., Mendoza, S., Lagaron, J. M., \& López-Rubio, A. (2015). Photoprotection of folic acid upon encapsulation in food-grade amaranth (amaranthus hypochondriacus L.) protein isolate - pullulan electrospun fibers. LWT - Food Science and Technology, 62, 970-975. 
571 Alborzi, S., Lim, L. -., \& Kakuda, Y. (2010). Electrospinning of sodium alginate-pectin ultrafine 572 fibers. Journal of Food Science, 75, C100-C107).

573 AOCS (1998a). AOCS Official Method Ce 2e66. Preparation of Methyl Esters of Long Chain Fatty 574 Champaign: AOCS Press.

575 AOCS (1998b). AOCS Official Method Ce 1be89. Fatty Acid Composition by GLC, Marine Oils. 576 Champaign: AOCS Press.

577 AOCS (1998c). AOCS Official method Ce 8-89. Determination of tocopherols and tocotrienols in 578 vegetable oils and fats by HPLC. Champaign: AOCS Press.

Arecchi, A., Mannino, S., \& Weiss, J. (2010). Electrospinning of Poly(vinyl alcohol) Nanofibers 580 Loaded with Hexadecane Nanodroplets. Journal of Food Science, 75, N80-N88.

Bakry, A. M., Fang, Z., Ni, Y., Cheng, H., Chen, Y. Q., \& Liang, L. (2016). Stability of tuna oil and 582 tuna oil/peppermint oil blend microencapsulated using whey protein isolate in combination with 583 carboxymethyl cellulose or pullulan. Food Hydrocolloids, 60, 559-571.

584 Barrow, C.J., Wang, B., Adhikari, B., \& Liu, H. (2013). Spray drying and encapsulation of omega-3 585 oils. In: C. Jacobsen, N. S. Nielsen, A. F. Horn, \& A.D.M. Sørensen (Eds.), Food Enrichment with 586 Omega-3 Fatty Acids (pp. 194-225). Cambridge: Woodhead Publishing Ltd.

Bhardwaj, N., \& Kundu, S. C. (2010). Electrospinning: A fascinating fiber fabrication technique. Biotechnology Advances, 28, 325-347.

Bligh, E. G., \& Dyer, W. J. (1959). A rapid method for total lipid extraction and purification. Canadian Journal of Biochemistry and Physiology, 37, 911-917.

591 Brahatheeswaran, D., Mathew, A., Aswathy, R. G., Nagaoka, Y., Venugopal, K., Yoshida, Y., et al. 592 (2012). Hybrid fluorescent curcumin loaded zein electrospun nanofibrous scaffold for biomedical 593 applications. Biomedical Materials, 7, 045001.

594 Chanamai, R., \& McClements, D. J. (2001). Depletion flocculation of beverage emulsions by gum 595 arabic and modified starch. Journal of Food Science, 66, 457-463. 
596 Cho, D., Netravali, A. N., \& Joo, Y. L. (2012). Mechanical properties and biodegradability of 597 electrospun soy protein Isolate/PVA hybrid nanofibers. Polymer Degradation and Stability, 97, 747598754.

599 Chronakis, I. S. (2010). Nano-microfibers by Electrospinning Technology: Processing, Properties and 600 Applications. In Y. Quin (Ed.), Micromanufacturing Engineering and Technology (pp. 264-286). 601 Oxford: Elsevier.

602 Comunian, T. A., \& Favaro-Trindade, C. S. (2016). Microencapsulation using biopolymers as an 603 alternative to produce food enhanced with phytosterols and omega-3 fatty acids: A review. Food 604 Hydrocolloids, 61, 442-457.

605 Encina, C., Vergara, C., Giménez, B., Oyarzún-Ampuero, F., \& Robert, P. (2016). Conventional 606 spray-drying and future trends for the microencapsulation of fish oil. Trends in Food Science \& 607 Technology, 56, 46-60.

608 Fathi, M., Martín, T., \& McClements, D. J. (2014). Nanoencapsulation of food ingredients using 609 carbohydrate based delivery systems. Trends in Food Science and Technology, 39, 18-39.

610 García-Moreno, P.J., Stephansen, K., Van Der Kruijs, J., Guadix, A., Guadix, E. M., Chronakis, I. S., 611 \& Jacobsen, C. (2016). Encapsulation of fish oil in nanofibers by emulsion electrospinning: Physical 612 characterization and oxidative stability. Journal of Food Engineering, 183, 39-49.

613 García-Moreno, P. J., Guadix, A., Guadix, E. M., \& Jacobsen, C. (2016). Physical and oxidative 614 stability of fish oil-in-water emulsions stabilized with fish protein hydrolysates. Food Chemistry, 203, 615 124-135.

616 Ghorani, B., \& Tucker, N. (2015). Fundamentals of electrospinning as a novel delivery vehicle for 617 bioactive compounds in food nanotechnology. Food Hydrocolloids, 51, 227-240.

618 GOED (2015). GOED Publishes Finished Product Report. URL

619 (http://goedomega3.com/index.php/the-goed-current-editorials/goed-publishes-finished-product620 report) (accessed October 2016). 
621 Gómez-Mascaraque, L. G., Sanchez, G., \& López-Rubio, A. (2016a). Impact of molecular weight on 622 the formation of electrosprayed chitosan microcapsules as delivery vehicles for bioactive compounds. 623 Carbohydrate Polymers, 150, 121-130.

624 Gomez-Mascaraque, L. G., Morfin, R. C., Pérez-Masiá, R., Sanchez, G., \& Lopez-Rubio, A. (2016b). 625 Optimization of electrospraying conditions for the microencapsulation of probiotics and evaluation of 626 their resistance during storage and in-vitro digestion. LWT - Food Science and Technology, 69, 438627446.

628 Gómez-Mascaraque, L. G., \& López-Rubio, A. (2016). Protein-based emulsion electrosprayed micro629 and submicroparticles for the encapsulation and stabilization of thermosensitive hydrophobic 630 bioactives. Journal of Colloid and Interface Science, 465, 259-270.

631 Guillén, M.D., \& Cabo, N. (1998). Relationships between the Composition of Edible Oils and Lard 632 and the Ratio of the Absorbance of Specific Bands of Their Fourier Transform Infrared Spectra. Role 633 of Some Bands of the Fingerprint Region. Journal of Agriculture and Food Chemistry, 46, 1788-1793.

634 Hamilton, R.J., \& Cast, J. (1999). Spectral properties of lipids. Boca Raton, CRC press.

635 Lertsutthiwong, P., \& Rojsitthisak, P. (2011). Chitosan-alginate nanocapsules for encapsulation of 636 turmeric oil. Pharmazie, 66, 911-915.

637 Li, J., He, A., Zheng, J., \& Han, C. C. (2006). Gelatin and gelatin - hyaluronic acid nanofibrous 638 membranes produced by electrospinning of their aqueous solutions. Biomacromolecules, 7, 22436392247.

640 Lim, L.T. (2015). Encapsulation of bioactive compounds using electrospinning and electrospraying 641 technologies. In C.M. Sabliov, H. Chen, R.Y. Yada (Eds.), Nanotechnology and Functional Foods: 642 Effective Delivery of Bioactive Ingredients (pp. 297-317). New York: John Wiley \& Sons.

643 Lopes Da Silva, J. A. (2012). Functional nanofibers in food processing. In Q. Wei (Ed.), Functional 644 nanofibers and their applications (pp. 262-304). Cambridge: Woodhead Publishing. 
645 López-Rubio, A., Sanchez, E., Wilkanowicz, S., Sanz, Y., \& Lagaron, J. M. (2012). Electrospinning 646 as a useful technique for the encapsulation of living bifidobacteria in food hydrocolloids. Food 647 Hydrocolloids, 28, 159-167.

648 López-Rubio, A., \& Lagaron, J. M. (2012). Whey protein capsules obtained through electrospraying 649 for the encapsulation of bioactives. Innovative Food Science and Emerging Technologies, 13, 200650206.

651 Matsumura, Y., Egami, M., Satake, C., Maeda, Y., Takahashi, T., Nakamura, A., \& Mori, T. (2003). 652 Inhibitory effects of peptide-bound polysaccharides on lipid oxidation in emulsions. Food Chemistry, $65383,107-119$.

654 Moomand, K., \& Lim, L. -. (2014). Oxidative stability of encapsulated fish oil in electrospun zein 655 fibres. Food Research International, 62, 523-532.

656 Moomand, K., \& Lim, L.-T. (2015). Effects of solvent and n-3 rich fish oil on physicochemical 657 properties of electrospun zein fibres. Food Hydrocolloids, 46, 191-200.

658 Neo, Y. P., Ray, S., Jin, J., Gizdavic-Nikolaidis, M., Nieuwoudt, M. K., Liu, D., et al. (2013). 659 Encapsulation of food grade antioxidant in natural biopolymer by electrospinning technique: a 660 physicochemical study based on zeinegallic acid system. Food Chemistry, 136, 1013-1021.

661 Park, J.K., \& Khan, T. (2009). Other microbial polysaccharides: pullulan, scleroglucan, elsinan, levan, 662 alternant, dextran. In: Phillips, G.O. and Williams, P.A. (Eds.), Handbook of Hydrocolloids (pp. 592663 614). Cambridge: Woodhead Publishing Ltd.

664 Pérez-Masiá, R., Lagaron, J. M., \& López-Rubio, A. (2014). Development and optimization of novel 665 encapsulation structures of interest in functional foods through electrospraying. Food and Bioprocess 666 Technology, 7, 3236-3245.

667 Pérez-Masiá, R., Lagaron, J. M., \& Lopez-Rubio, A. (2014). Surfactant-aided electrospraying of low 668 molecular weight carbohydrate polymers from aqueous solutions. Carbohydrate Polymers, 101, 249669255. 
670 Pérez-Masiá, R., Lagaron, J. M., \& López-Rubio, A. (2015). Morphology and stability of edible

671 lycopene-containing micro- and nanocapsules produced through electrospraying and spray drying.

672 Food and Bioprocess Technology, 8, 459-470.

673 Ramakrishna, S. (2005). An Introduction to Electrospinning and Nanofibers. Singapore: World 674 Scientific.

675 Ritcharoen, W., Thaiying, Y., Saejeng, Y., Jangchud, I., Rangkupan, R., Meechaisue, C., \& Supaphol, 676 P. (2008). Electrospun dextran fibrous membranes. Cellulose, 15, 435-444.

677 Serfert, Y., Drusch, S., \& Schwarz, K. (2009). Chemical stabilisation of oils rich in long-chain 678 polyunsaturated fatty acids during homogenisation, microencapsulation and storage. Food Chemistry, $679113,1106-1112$

680 Singh, H., \& Ye, A. (2009). Interactions and Functionality of Milk Proteins in Food Emulsions. In A. 681 Thompson, M. Boland, H. Singh (Eds.), Milk Proteins: From Expression To Food (pp. 321-345). 682 London: Elsevier Academic Press Inc.

683 Shahidi, F. (2015). Omega-3 fatty acids and marine oils in cardiovascular and general health: A 684 critical overview of controversies and realities. Journal of Functional Foods, 19, 797-800.

685 Shantha, N. C., \& Decker, E. A. (1994). Rapid, sensitive, iron-based spectrophotometric methods for 686 determination of peroxide values of food lipids. Journal of AOAC International, 77, 421-424.

687 Stijnman, A. C., Bodnar, I., \& Hans Tromp, R. (2011). Electrospinning of food-grade polysaccharides. 688 Food Hydrocolloids, 25, 1393-1398.

689 Tong, L. M., Sasaki, S., McClements, D. J., \& Decker, E. A. (2000). Mechanisms of the antioxidant 690 activity of a high molecular weight fraction of whey. Journal of Agricultural and Food Chemistry, 48, 691 1473-1478.

692 Torres-Giner, S., Martinez-Abad, A., Ocio, M. J., \& Lagaron, J. M. (2010). Stabilization of a 693 nutraceutical omega-3 fatty acid by encapsulation in ultrathin electrosprayed zein prolamine. Journal 694 of Food Science, 75, N69-N79. 
695 Weiss, J., Kanjanapongkul, K., Wongsasulak, S., \& Yoovidhya, T. (2012). Electrospun fibers: 696 Fabrication, functionalities and potential food industry applications. In Q. Huang (Ed.), 697 Nanotechnology in the food, beverage and nutraceutical industries (pp. 362-397). Cambrdige: 698 Woodhead Publishing Ltd.

699 Wongsasulak, S., Patapeejumruswong, M., Weiss, J., Supaphol, P., \& Yoovidhya, T. (2010). 700 Electrospinning of food-grade nanofibers from cellulose acetate and egg albumen blends. Journal of $701 \quad$ Food Engineering, 98, 370-376.

702 Yang, J.-M., Zha, L.-S., Yu, D.-G., \& Liu, J. (2013). Coaxial electrospinning with acetic acid for 703 preparing ferulic acid/zein composite fibers with improved drug release profiles. Colloids and 704 Surfaces B: Biointerfaces, 102, 737e743. 


\section{FIGURE AND TABLE CAPTIONS}

- Figure 1. SEM images of 5 wt.\% pullulan (A), 10 wt.\% pullulan (B), 15 wt.\% pullulan (C), 20 wt.\% dextran70 (D), 30 wt.\% dextran70 (E), 40 wt.\% dextran70 (F), 10 wt.\% dextran500 (G), 20 wt.\% dextran500 (H), 30 wt.\% dextran500 (I), 10 wt.\% WPC (J), 20 wt.\% WPC (K), and 30 wt.\% WPC (L).

- Figure 2. Peroxide value during storage of biopolymers solutions (15 wt.\% pullulan, $30 \mathrm{wt} . \%$ dextran70, 20 wt.\% dextran500, 30 wt.\% WPC) containing fish oil. Emulsion was evaluated as a control.

- Figure 3. Volatiles content during storage of biopolymers solutions (15 wt.\% pullulan, $30 \mathrm{wt} \%$ dextran70, 20 wt.\% dextran500, 30 wt.\% WPC) containing fish oil. Emulsion was evaluated as a control.

- Figure 4. Morphology and diameter distribution of pullulan fibers produced at lab scale: a) control, b) emulsified, c) neat, d) fiber average diameter distribution, e) standard deviation from average diameter, and f) bead diameter distribution.

- Figure 5. Morphology of dextran capsules produced at lab scale: a) control, b) emulsified, and c) neat, and d) diameter distribution.

- Figure 6. AFTR-FITR spectra of NMS produced at pilot-plant scale: a) pullulan fibers, and b) dextran capsules.

- Figure 7. Wet-STEM in E-SEM image of NMS containing neat oil: a) pullulan fibers, and b) dextran capsules.

- Table 1. Solution properties of biopolymer solutions containing emulsified fish oil.

- Table 2. Content of primary and secondary oxidation products of selected NMS after production. 
Table 1. Solution properties of biopolymer solutions containing emulsified fish oil.

\begin{tabular}{|c|c|c|c|c|}
\hline \multicolumn{2}{|r|}{ Sample } & \multirow{2}{*}{$\begin{array}{l}\text { Viscosity } \\
\qquad(\mathrm{cP})\end{array}$} & \multirow{2}{*}{$\begin{array}{l}\text { Surface tension } \\
\qquad(\mathrm{mN} / \mathrm{m})\end{array}$} & \multirow{2}{*}{$\begin{array}{c}\text { Conductivity } \\
\qquad(\mu \mathrm{S} / \mathrm{cm})\end{array}$} \\
\hline Polymer & Concentration (wt.\%) & & & \\
\hline & Emulsion & $3.9 \pm 0.1\left(100 \mathrm{~s}^{-1}\right)^{*}$ & $46.5 \pm 0.1$ & $921.0 \pm 1.4$ \\
\hline \multirow{3}{*}{ Pullulan } & 5 & $23.6 \pm 0.3^{a}$ & $55.5 \pm 0.1^{a}$ & $30.8 \pm 0.1^{a}$ \\
\hline & 10 & $179.0 \pm 0.2^{b}$ & $56.6 \pm 0.2^{b}$ & $39.9 \pm 0.3^{b}$ \\
\hline & 15 & $1,040.0 \pm 26.0^{c}$ & $54.1 \pm 0.3^{\mathrm{c}}$ & $128.3 \pm 1.7^{c}$ \\
\hline \multirow{3}{*}{ Dextran70 } & 20 & $44.3 \pm 1.9^{a}$ & $40.6 \pm 1.4^{a}$ & $47.0 \pm 0.1^{\mathrm{a}}$ \\
\hline & 30 & $201.3 \pm 1.4^{b}$ & $23.1 \pm 0.5^{b}$ & $46.0 \pm 0.2^{b}$ \\
\hline & 40 & $1,146.8 \pm 13.5^{c}$ & $18.5 \pm 0.8^{c}$ & $34.5 \pm 0.1^{c}$ \\
\hline \multirow{3}{*}{ Dextran500 } & 10 & $29.5 \pm 0.1^{a}$ & $49.2 \pm 0.2^{\mathrm{a}}$ & $4,690.0 \pm 0.1^{a}$ \\
\hline & 20 & $181.4 \pm 4.3^{\mathrm{b}}$ & $48.3 \pm 0.1^{b}$ & $8,210.0 \pm 14.1^{\mathrm{b}}$ \\
\hline & 30 & $1,096.5 \pm 31.5^{c}$ & $47.6 \pm 0.1^{c}$ & $7,315.0 \pm 21.2^{c}$ \\
\hline \multirow{3}{*}{ WPC } & 10 & $4.3 \pm 0.2^{a}\left(100 \mathrm{~s}^{-1}\right)^{*}$ & $44.9 \pm 0.1^{\mathrm{a}}$ & $4,385 \cdot 0 \pm 91.9^{a}$ \\
\hline & 20 & $13.5 \pm 0.3^{b}$ & $44.0 \pm 0.1^{\mathrm{b}}$ & $6,580.0 \pm 14.1^{\mathrm{b}}$ \\
\hline & 30 & $66.0 \pm 0.1^{\mathrm{c}}$ & $48.5 \pm 0.2^{c}$ & $7,160 \cdot 0 \pm 0.0^{c}$ \\
\hline
\end{tabular}

Different superscript letters within the same column and the same biopolymer indicate significant differences $(\mathrm{p}<0.05)$.

*Solutions exhibiting shear thinning behavior. 
Table 2. Content of primary and secondary oxidation products of selected NMS after production.

\begin{tabular}{|c|c|c|c|c|c|c|c|}
\hline \multirow{2}{*}{ Polymer } & \multirow{2}{*}{ Equipment } & \multirow{2}{*}{ Oil incorporation } & \multirow{2}{*}{ Batch, min } & \multirow{2}{*}{$\mathrm{PV}$, meq $\mathrm{O}_{2} / \mathrm{kg}$} & \multicolumn{3}{|c|}{ Volatiles, ng/g sample } \\
\hline & & & & & 1-penten-3-ol & Hexanal & Nonanal \\
\hline \multirow{7}{*}{ Pullulan } & \multirow{4}{*}{ Lab scale } & Emulsified & 120 & $69.2 \pm 4.2^{a}$ & $131.8 \pm 18.1^{\mathrm{a}}$ & $150.7 \pm 13.1^{\mathrm{a}}$ & $1106.8 \pm 85.7^{a}$ \\
\hline & & Emulsified & 30 & $49.4 \pm 5.9^{b}$ & $93.5 \pm 5.9^{b}$ & $99.1 \pm 7.1^{b}$ & $990.1 \pm 32.4^{a}$ \\
\hline & & Neat & 120 & $37.0 \pm 3.2^{c}$ & $24.4 \pm 11.7^{c, d}$ & $140.9 \pm 1.8^{a, c}$ & $2575.0 \pm 482.3^{b}$ \\
\hline & & Neat & 30 & $12.3 \pm 0.9^{d}$ & $15.5 \pm 5.1^{\mathrm{c}, \mathrm{d}}$ & $104.4 \pm 28.5^{\mathrm{b}, \mathrm{c}}$ & $1574.9 \pm 356.1^{\mathrm{a}, \mathrm{c}}$ \\
\hline & \multirow{3}{*}{ Pilot-plant scale } & Control & & - & $1.0 \pm 1.4^{\mathrm{c}}$ & $60.7 \pm 13.5^{\mathrm{d}}$ & $1278.7 \pm 340.3^{\mathrm{a}, \mathrm{c}}$ \\
\hline & & Emulsified & 10 & $24.8 \pm 4.5^{d}$ & $63.2 \pm 2.3^{\mathrm{e}}$ & $158.1 \pm 9.2^{a}$ & $1944.4 \pm 152.1^{b, c}$ \\
\hline & & Neat & & $16.0 \pm 2.2^{\mathrm{d}, \mathrm{e}}$ & $33.7 \pm 0.4^{d}$ & $87.6 \pm 1.1^{b, d}$ & $881.5 \pm 136.7^{a}$ \\
\hline \multirow{5}{*}{ Dextran } & \multirow{2}{*}{ Lab scale } & Emulsified & \multirow{2}{*}{120} & $48.1 \pm 4.0^{\mathrm{a}, \mathrm{b}}$ & $85.7 \pm 1.5^{\mathrm{a}}$ & $104.7 \pm 2.9^{\mathrm{a}, \mathrm{b}}$ & $1250.0 \pm 35.6^{\mathrm{a}}$ \\
\hline & & Neat $^{*}$ & & $43.9 \pm 19.8^{\mathrm{a}, \mathrm{b}}$ & $5.1 \pm 4.8^{b}$ & $51.5 \pm 24.5^{\mathrm{a}}$ & $429.6 \pm 182.8^{b}$ \\
\hline & \multirow{3}{*}{ Pilot-plant scale } & Control & & - & $3.9 \pm 3.2^{b}$ & $115.1 \pm 6.4^{b}$ & $2264.2 \pm 190.0^{c}$ \\
\hline & & Emulsified & 10 & $62.3 \pm 4.5^{\mathrm{b}}$ & $136.8 \pm 8.6^{c}$ & $513.6 \pm 12.0^{c}$ & $12281.8 \pm 196.5^{d}$ \\
\hline & & Neat ${ }^{*}$ & & $21.2 \pm 9.5^{a}$ & $113.3 \pm 12.0^{d}$ & $634.7 \pm 44.3^{d}$ & $9122.9 \pm 180.0^{e}$ \\
\hline
\end{tabular}

Different superscript letters within the same column and the same biopolymer indicate significant differences $(\mathrm{p}<0.05)$.

*Phase separation of solution. 

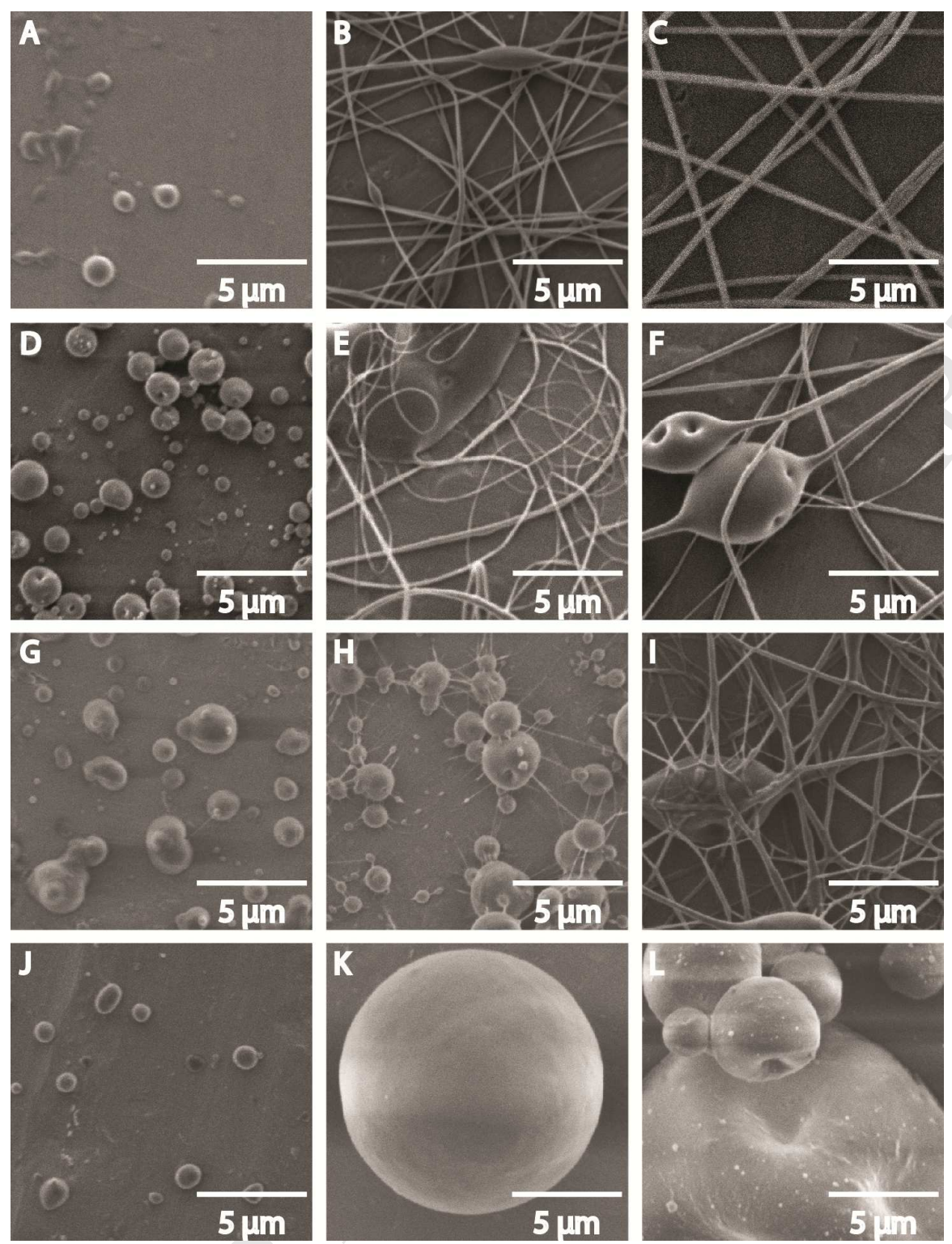

Fig. 1. SEM images of 5 wt.\% pullulan (A), 10 wt.\% pullulan (B), 15 wt.\% pullulan (C), 20 wt.\% dextran70 (D), 30 wt.\% dextran70 (E), 40 wt.\% dextran70 (F), 10 wt.\% dextran500 (G), 20 wt.\% dextran500 (H), 30 wt.\% dextran500 (I), 10 wt.\% WPC (J), 20 wt.\% WPC (K), and 30 wt.\% WPC (L). 


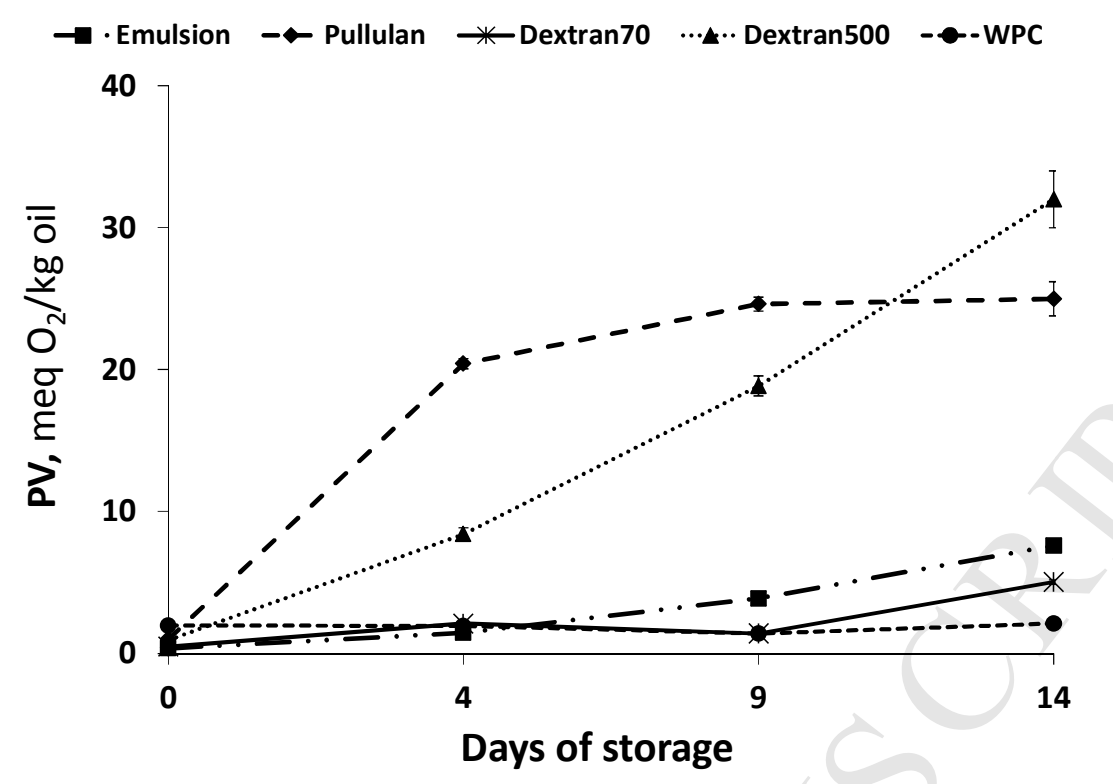

Fig. 2. Peroxide value during storage of biopolymers solutions ( $15 \mathrm{wt} . \%$ pullulan, $30 \mathrm{wt} . \%$ dextran70, $20 \mathrm{wt} . \%$ dextran500, $30 \mathrm{wt} . \%$ WPC) containing fish oil. Emulsion was evaluated as a control. 
a)

$\rightarrow$ Emulsion $-\leftarrow$ Pullulan $*$ Dextran70 ...... Dextran500 -๑-WPC

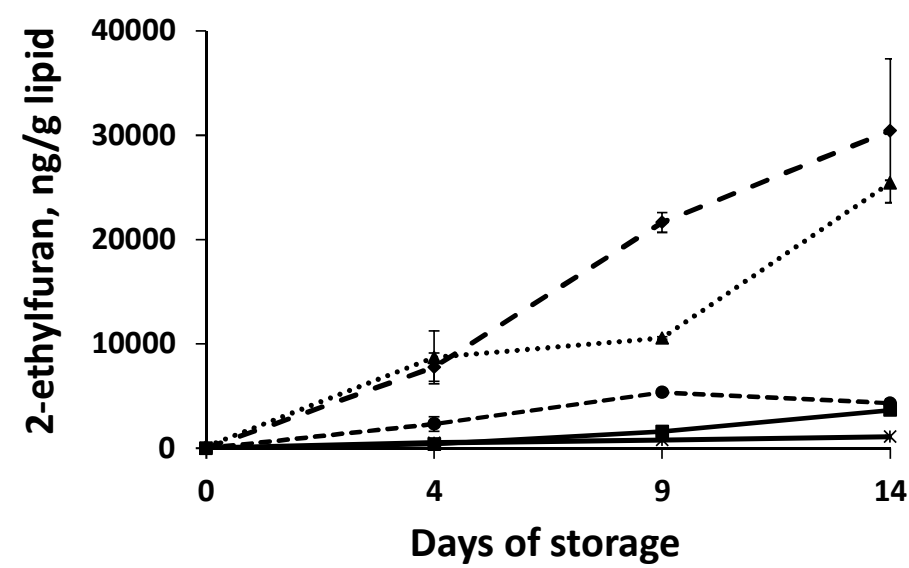

c)
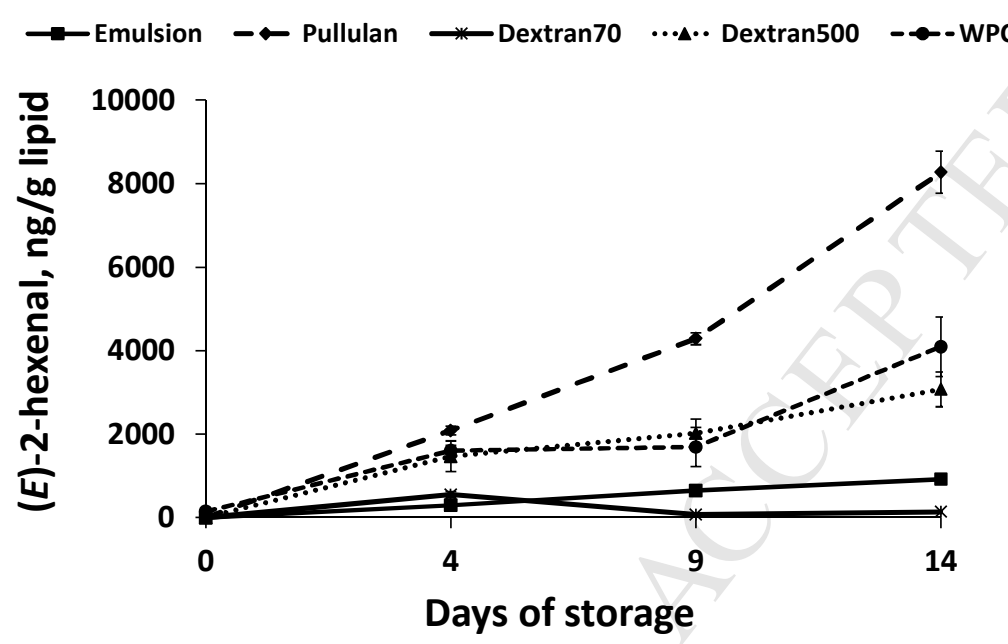

b)

$\rightarrow$ Emulsion $-\leftarrow$ Pullulan $\rightarrow$ Dextran70 ….. Dextran500 - - WPC

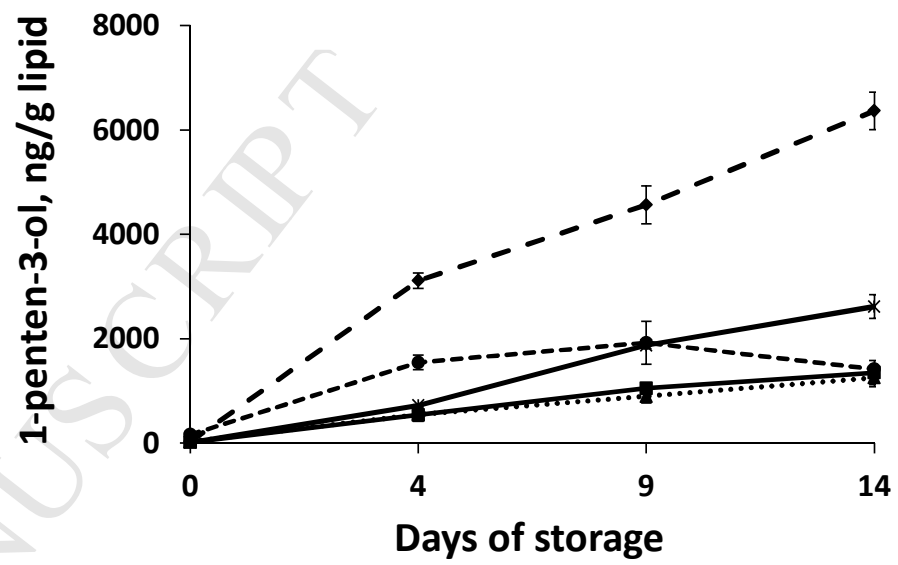

d)

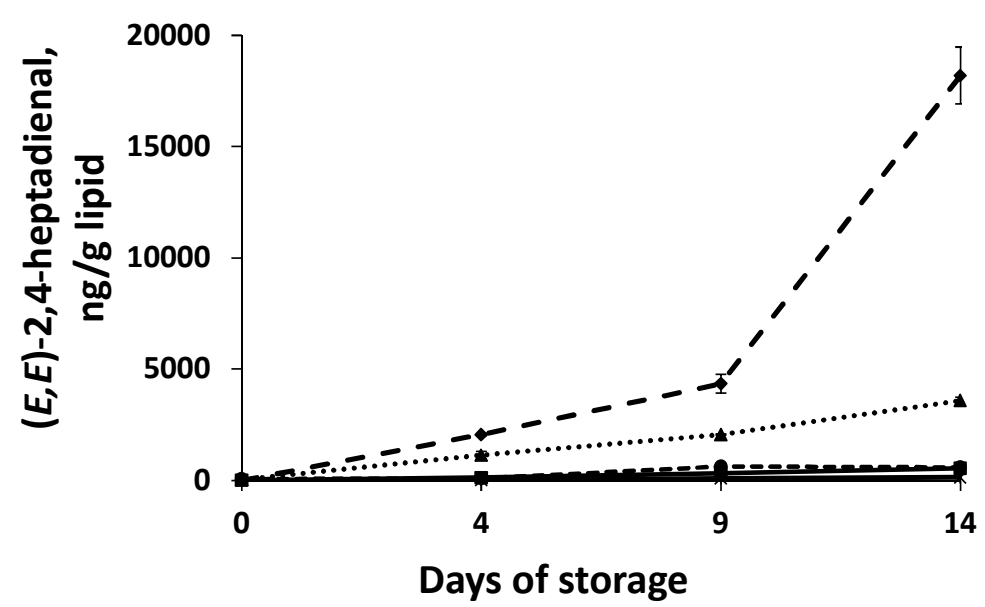

Fig. 3. Volatiles content during storage of biopolymers solutions (15 wt. $\%$ pullulan, $30 \mathrm{wt} . \%$ dextran70, $20 \mathrm{wt} . \%$ dextran500, $30 \mathrm{wt} . \% \mathrm{WPC}$ ) containing fish oil. Emulsion was evaluated as a control. 
a)

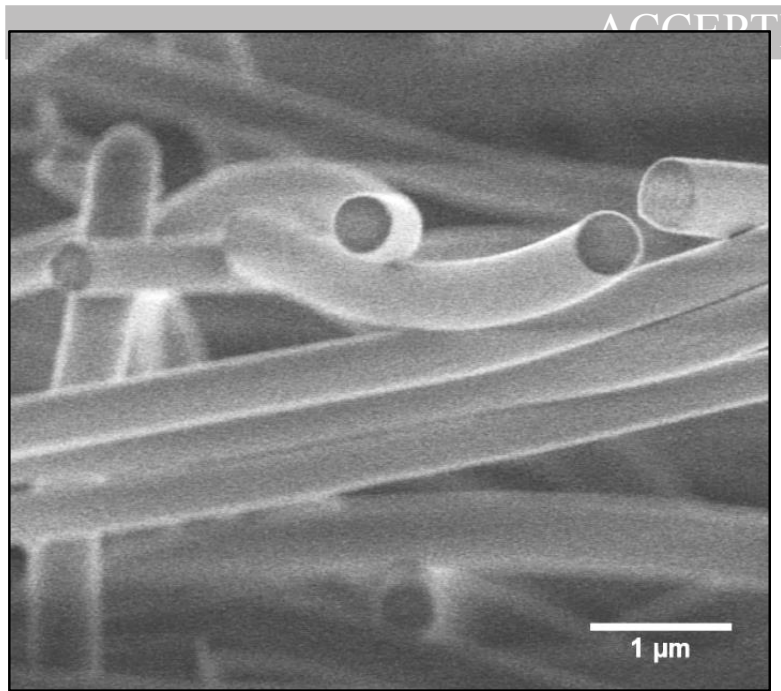

b)

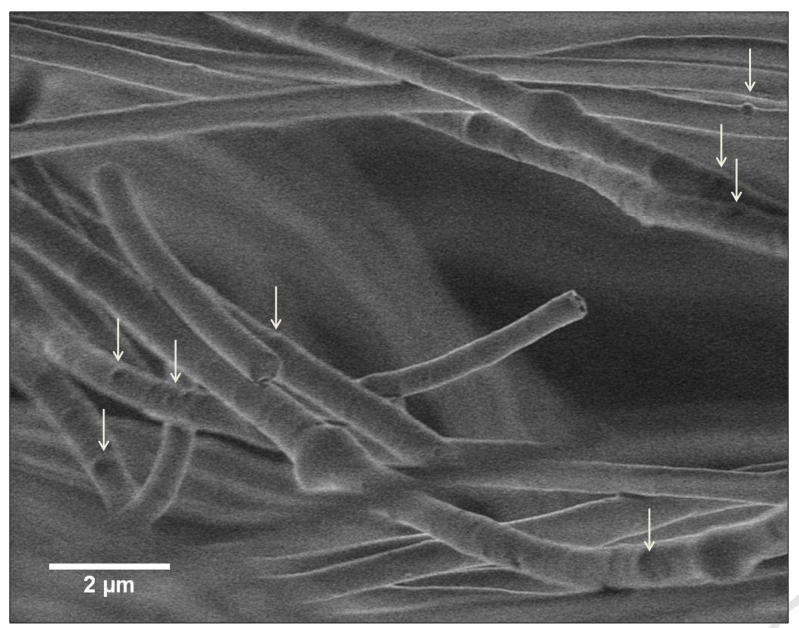

c)

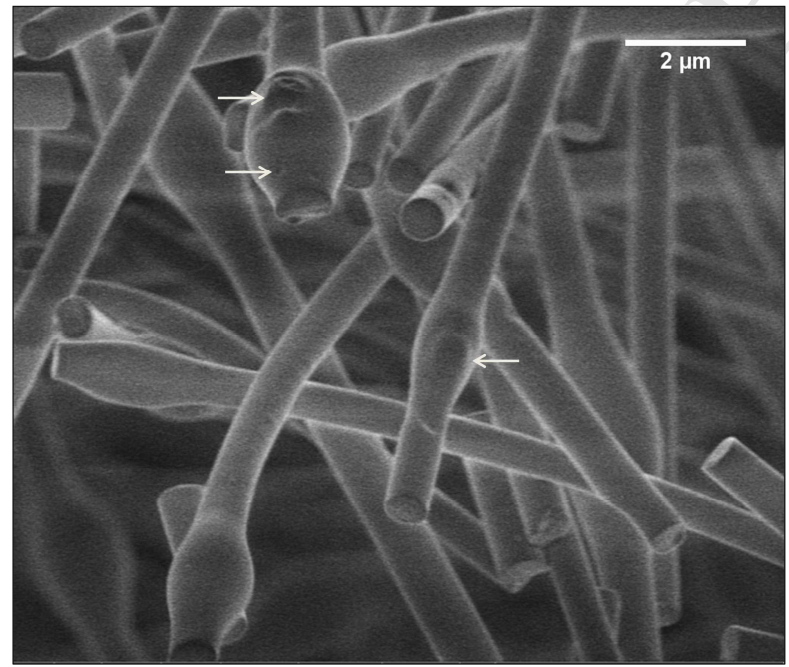

d)

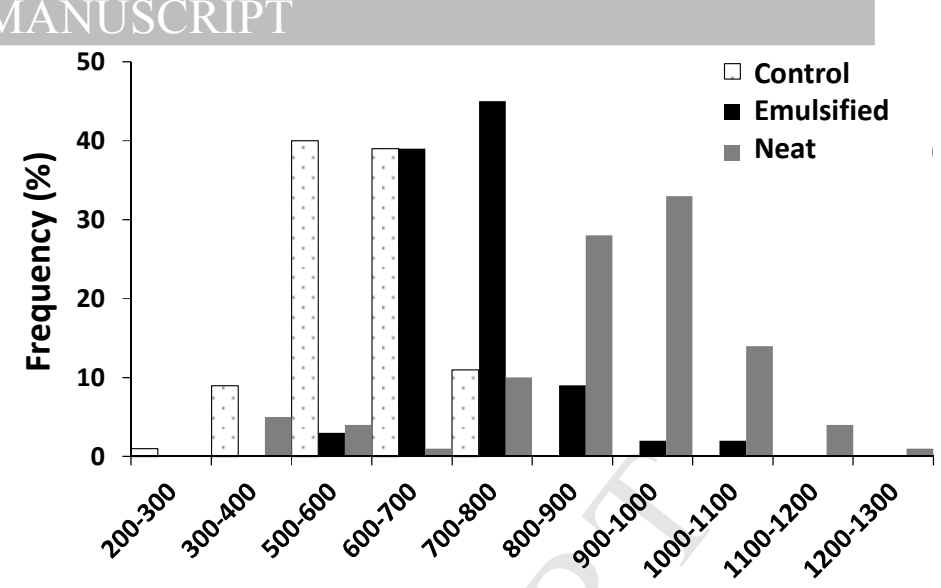

Fiber Average Diameter (nm)

e)

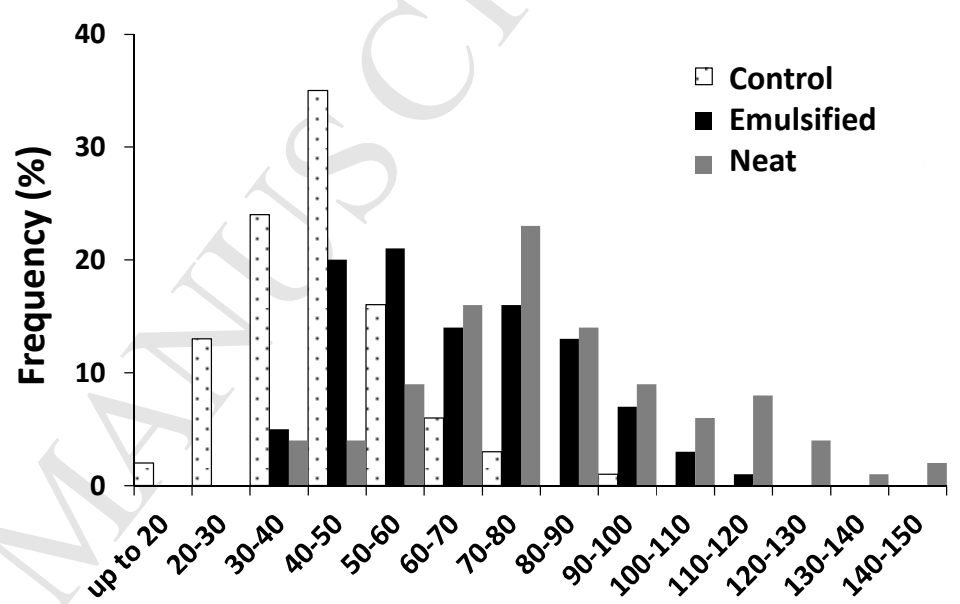

Fiber standard deviation (nm)

f)

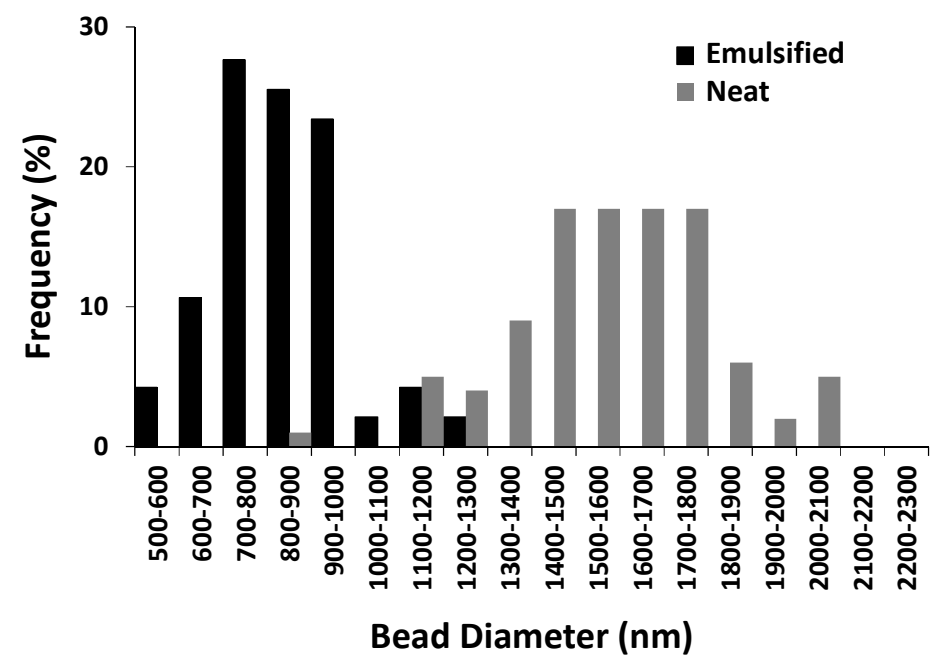

Fig. 4. Morphology and diameter distribution of pullulan fibers produced at lab scale: a) control, b) emulsified, c) neat, d) fiber average diameter distribution, e) standard deviation from average diameter, and f) bead diameter distribution.

The standard deviation from fiber average diameter was calculated by measuring each fiber at 10 different points. A total of one hundred random fibers were measured for this purpose. 
a)

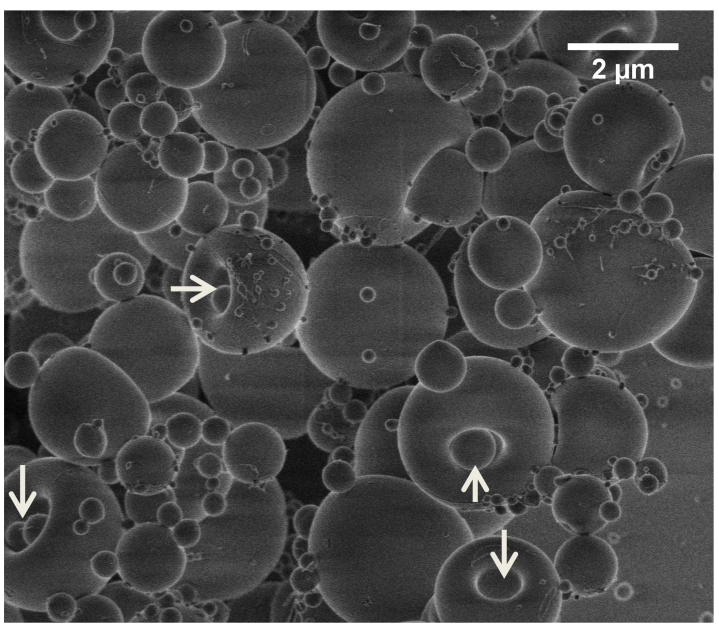

c)

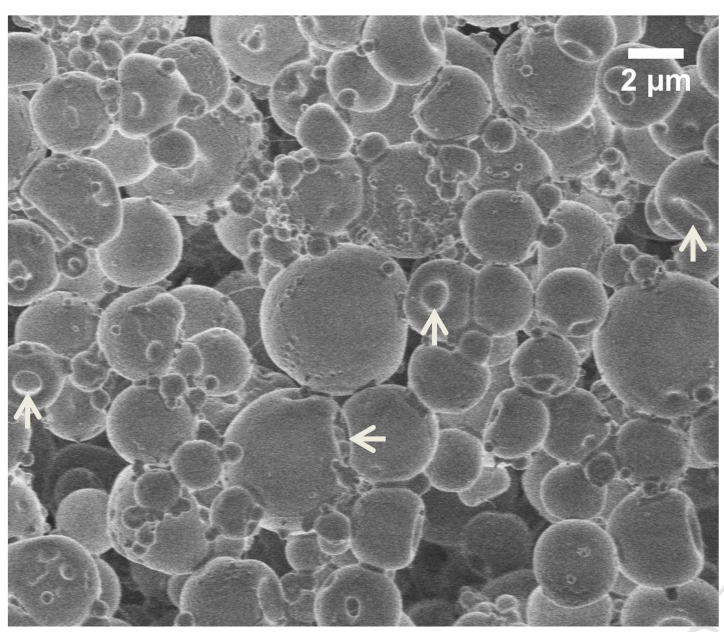

b)

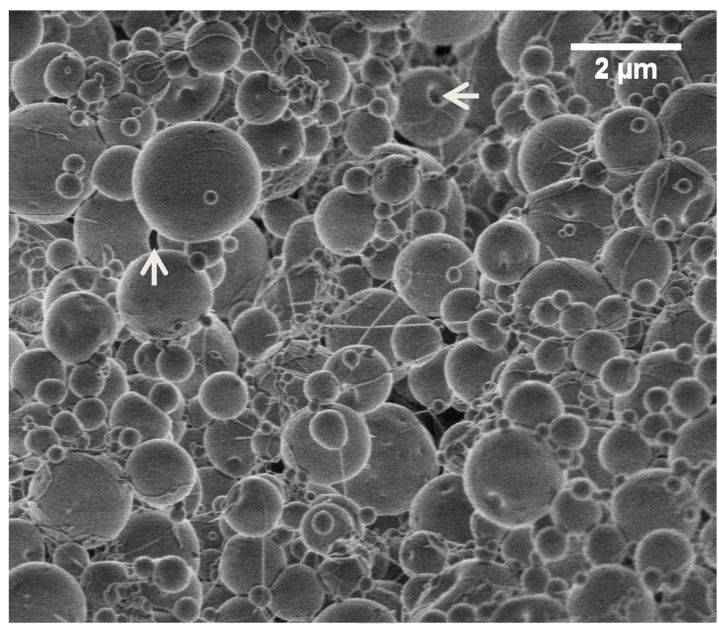

d)

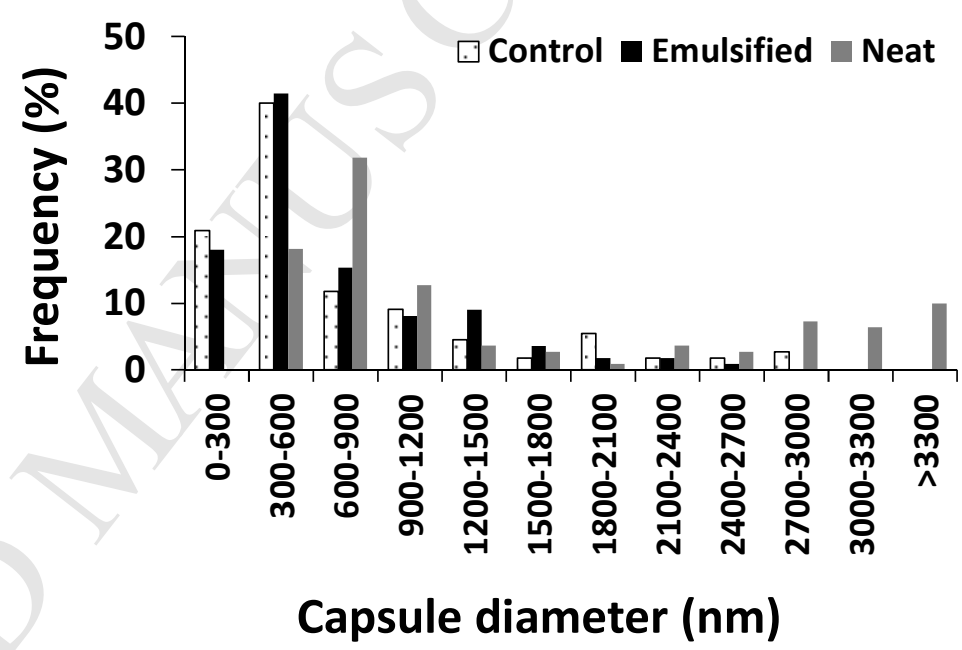

Fig. 5. Morphology of dextran capsules produced at lab scale: a) control, b) emulsified, and c) neat, and d) diameter distribution. 
a)

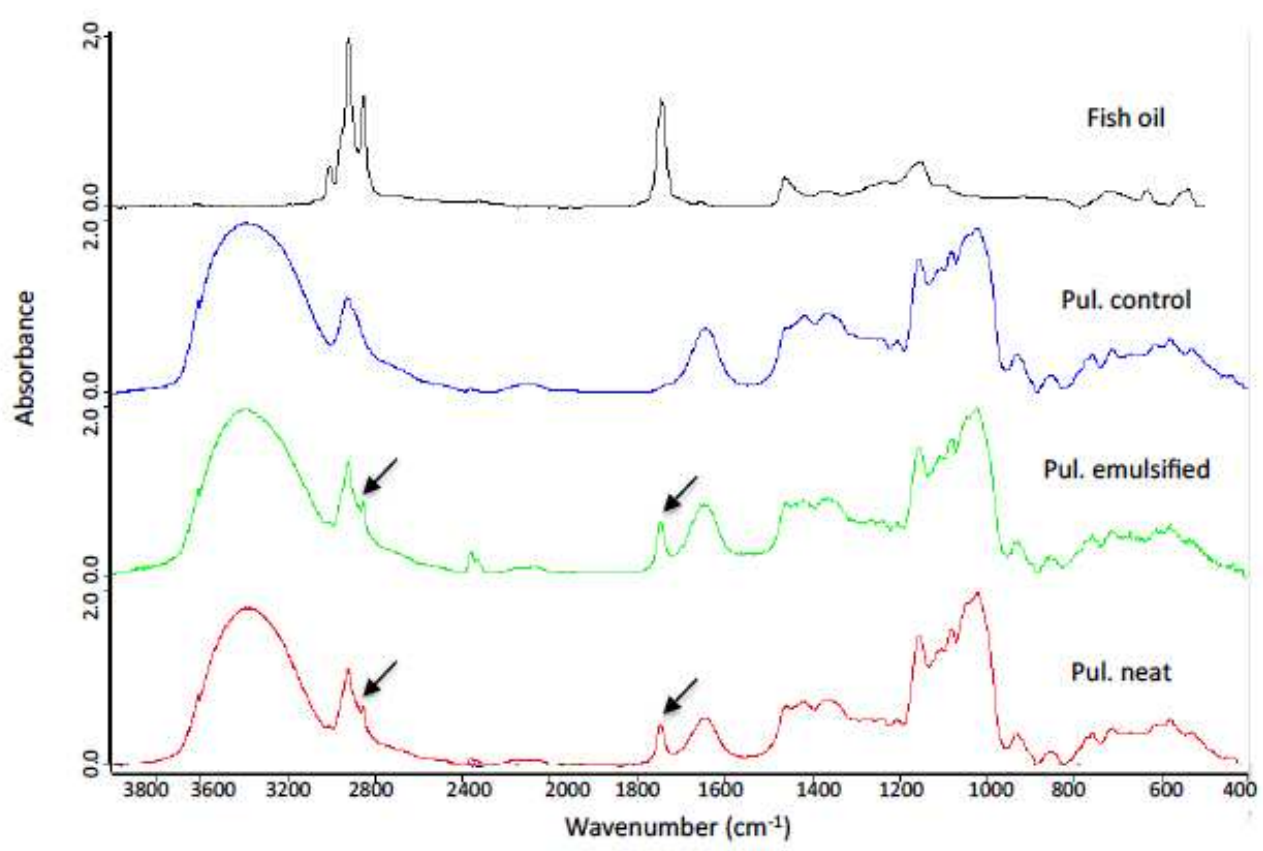

b)

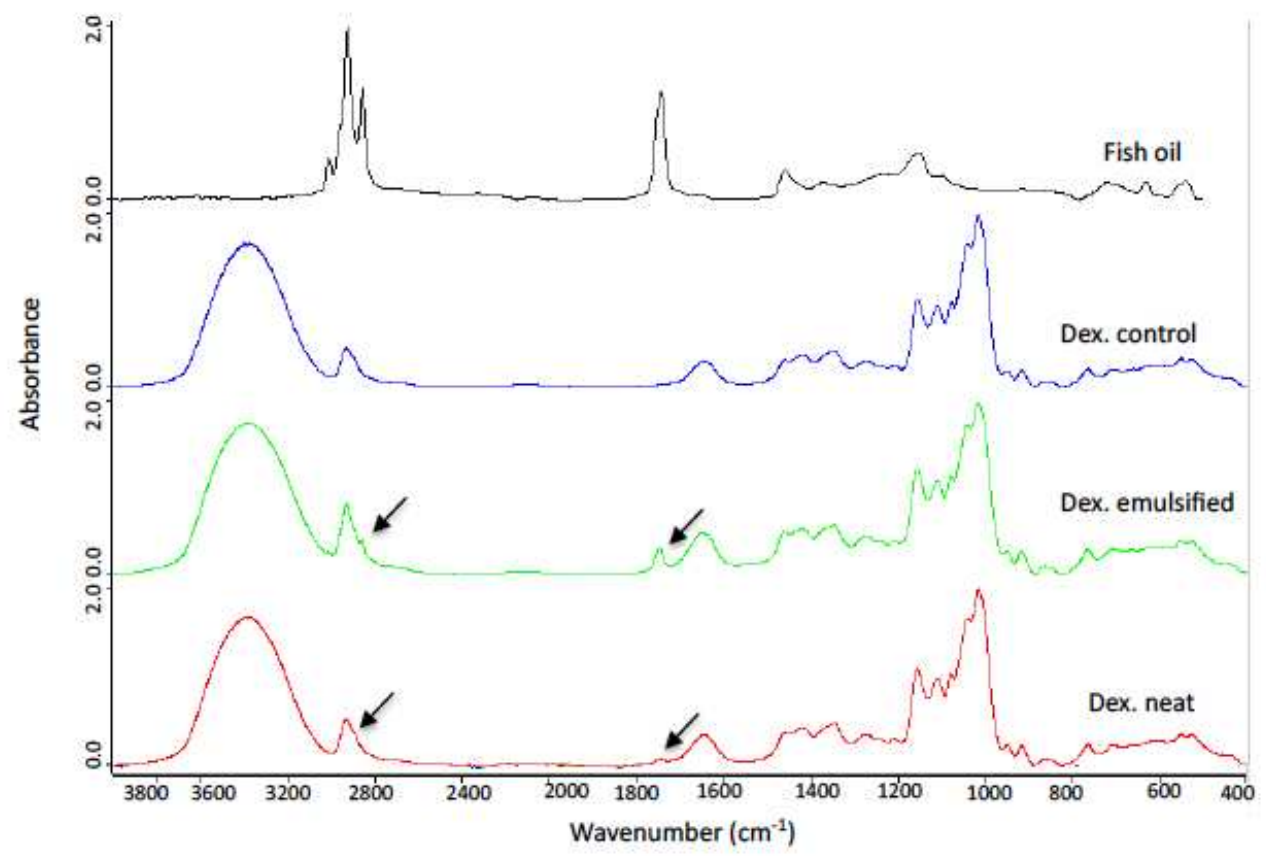

Fig. 6. AFTR-FITR spectra of NMS produced at pilot-plant scale: a) pullulan fibers, and b) dextran capsules. 
a)

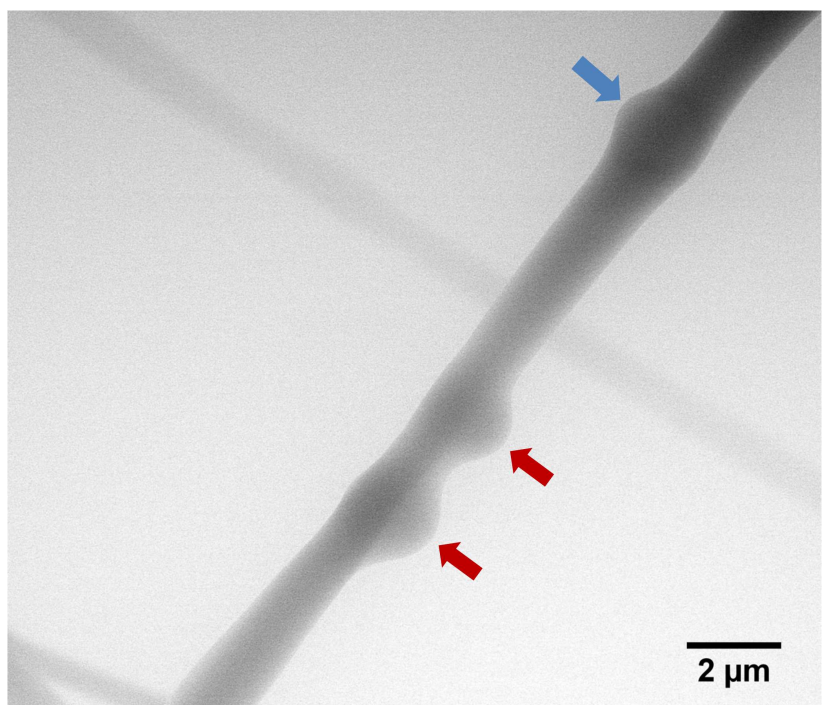

b)

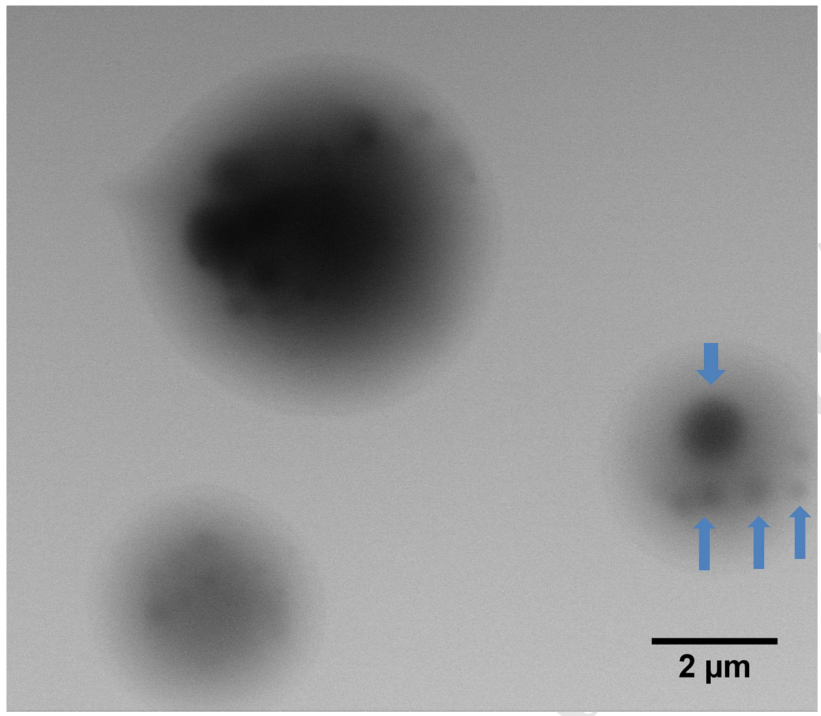

Fig. 7. Wet-STEM in E-SEM image of NMS containing neat oil: a) pullulan fibers, and b) dextran capsules. 


\section{Highlights}

- Fish oil-loaded nanofibers were produced by electrospinning using pullulan

- Fish oil-loaded capsules were obtained by electrospraying using dextran

- Opened dextran-capsules with poor oxidative stability were obtained

- Oxidatively stable pullulan fibers were produced using neat oil and short batches

- These pullulan nanofibers entrapped the oil efficiently in large bead-structures 